إشكالية الكتابة وتثثلات الحماثة وما بعد الحداثة وما بعدهما: قراءة نقدية في رواية "ماو الثالي" (Mao II)

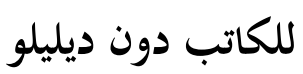

\title{
The Problem of Writing and Representations of Modernity, Postmodernism and Beyond: A Critical Reading in the Novel "Mao II" by Don DeLillo
}

\author{
Laila M. al-Sharqi
}

Department of European Languages \& Literature, King Abdul Aziz University, Saudi Arabia lzayan@kau.edu.sa

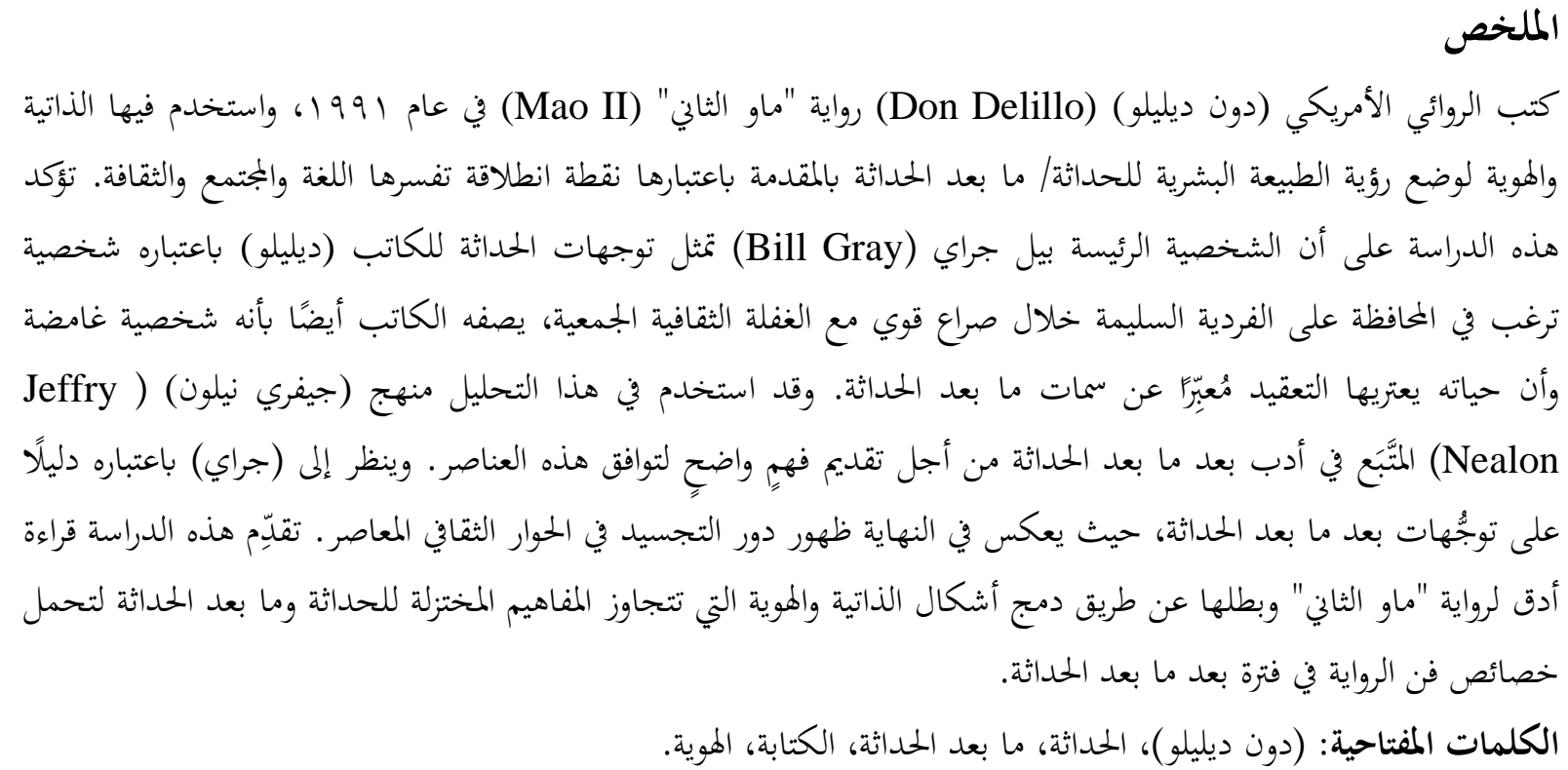

\begin{abstract}
The American novelist, Don DeLillo, wrote the novel, Mao II (1991), which uses selfhood and identity to foreground the modern/postmodern vision of human nature as a tabula rasa that is constructed by language, society, and culture. This study argues that while the novel's protagonist, Bill Gray, represents DeLillo's modernist tendencies, as the character desires to maintain authentic individualism during a fierce struggle with his culture's collective mindlessness, DeLillo also describes an ambiguous character, whose life and works complexly exhibit and engage with postmodernist features. Jeffry Nealon's approach to postpostmodernist literature and post-humanist scholarship are utilized in this analysis to provide a clearer understanding on the convergence of these components. Gray is examined as a manifestation of post-postmodernist tendencies, who ultimately reflects the emerging role of embodiment in contemporary cultural discourse. This study not only elucidates the fundamental changes that society currently faces but also provides a closer reading of the novel and its protagonist by incorporating forms of selfhood and identity that extend beyond reductive modernist and postmodernist conceptions to carry elements of post-postmodernist literature.
\end{abstract}

Keywords: Don Delillo, modernism, postmodernism, authorship, identity. 
DOI: https://doi.org/10.22452/aldad.vol5no1.2

e-ISSN: 2637-1146

https://ejournal.um.edu.my/index.php/aldaad/index

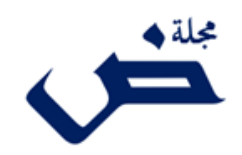

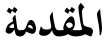

(دون ديليلو) روائي أمريكي من كتاب ما بعد الحداثة، صدرت له العديد من الروايات مثل: "الصخب الأبيض"

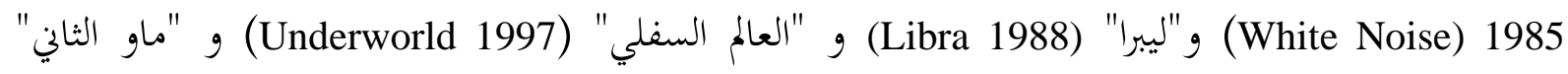
11 (Mao II 1991)

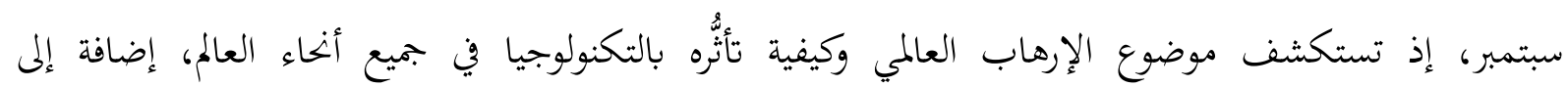

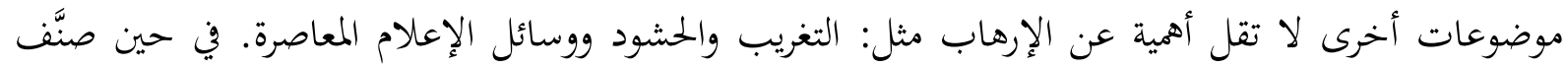

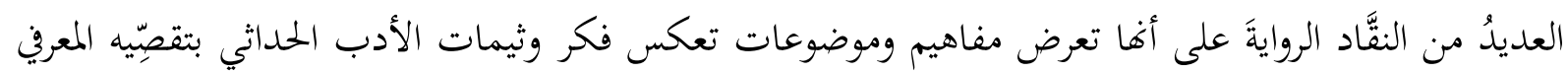

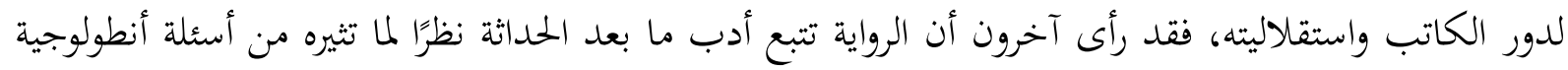

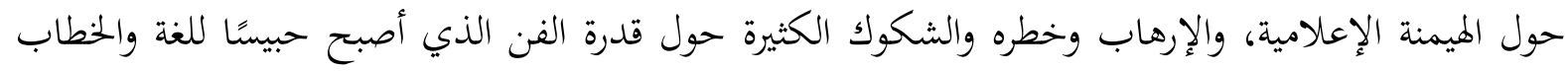

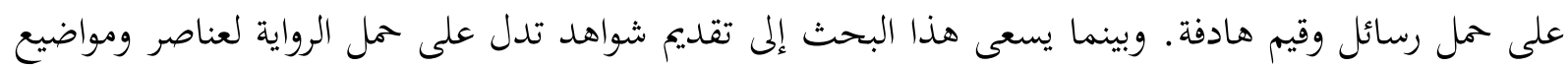

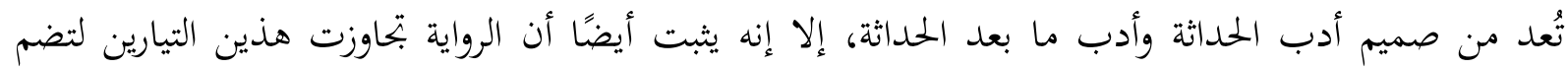

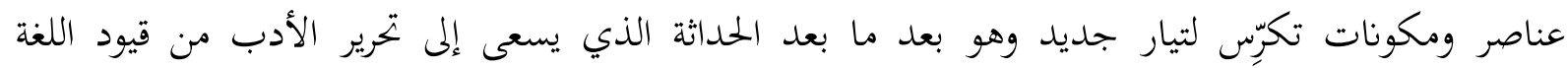

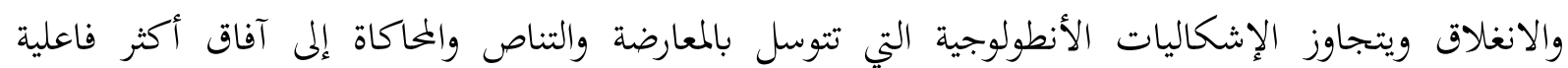
وعقلانية تعمل على رأب الصَّدع بين الوعي البشري والعالم الخارجي.

تستمد الرواية عنواها من بجموعة الصور الشخصية "ماو زيدونج" التي طبعها الفنان الشهير (أندي

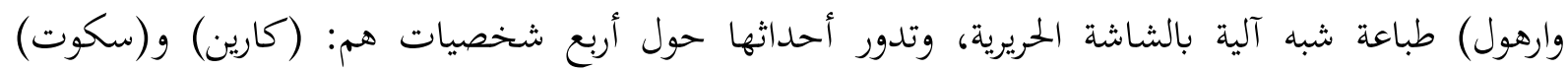

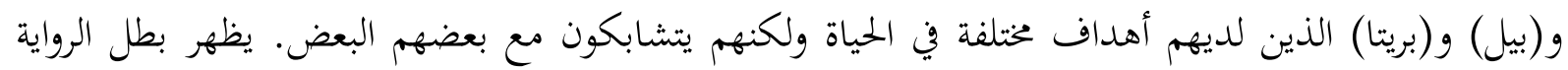

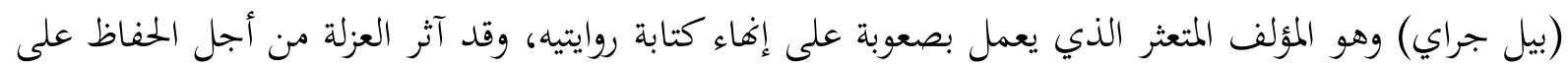

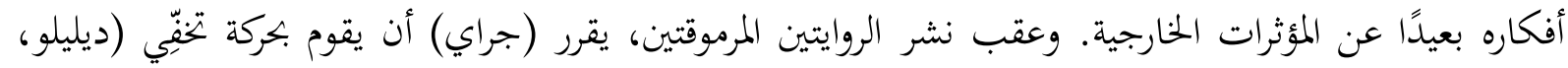

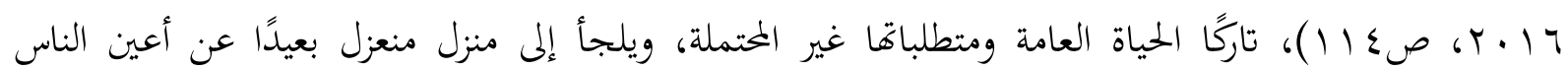
ووسائل الإعلام. ويقوم (سكوت مارتينيو) بمساعدة (جراي) في الكتابة والتصحيح ومراجعة مسودة روايته الثالثة

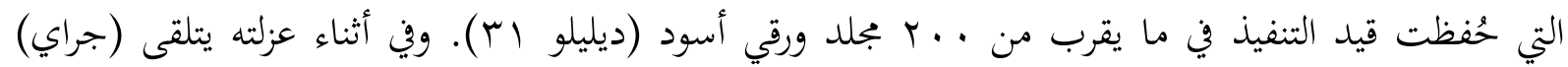

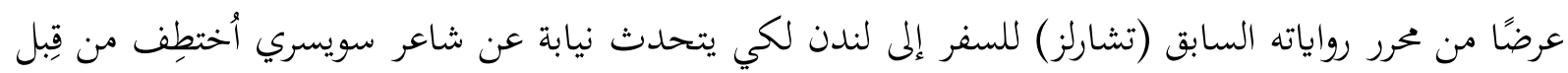

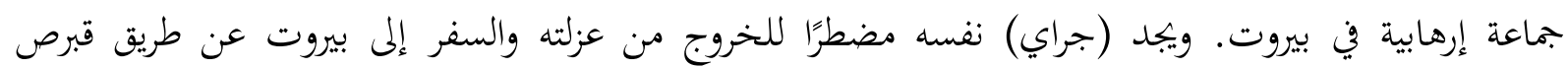

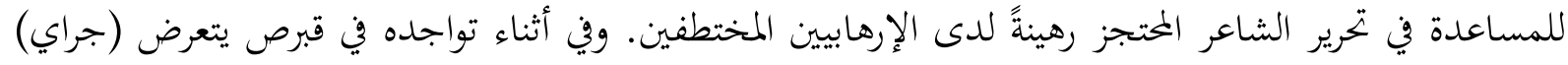
لحادث مروري مروّع يتسبب في مضاعفات خطيرة في كبده مما يؤدي إلى وفاته. 
DOI: https://doi.org/10.22452/aldad.vol5no1.2

e-ISSN: 2637-1146

https://ejournal.um.edu.my/index.php/aldaad/index

تحدف هذه الدراسة لمناقشة الوسائل المعقدة التي واجه من خلالالها (ديليلو) مشكلة التأليف والكتابة في

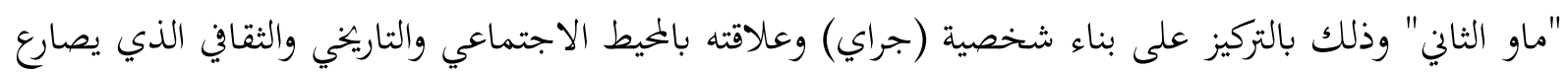

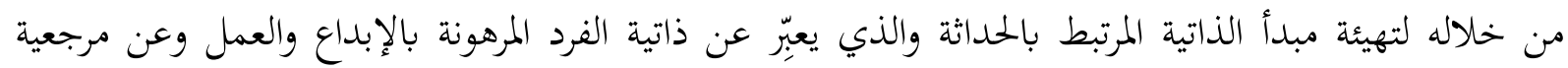

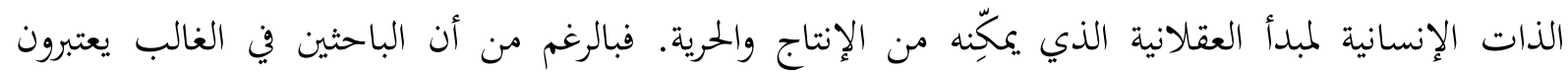

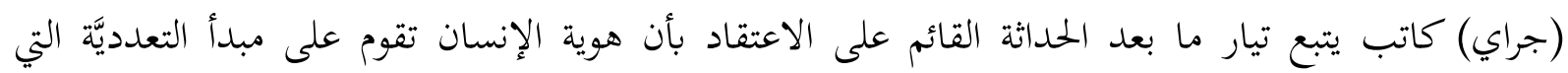

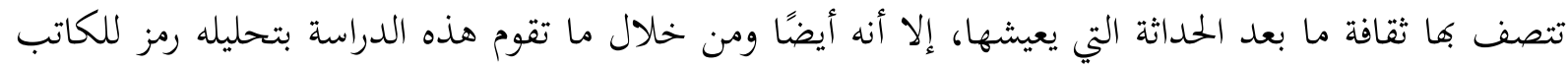

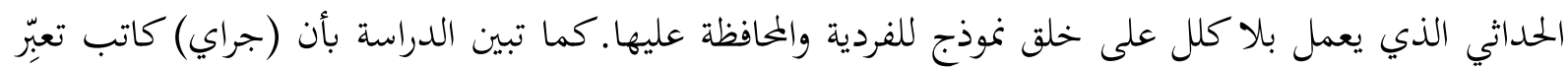

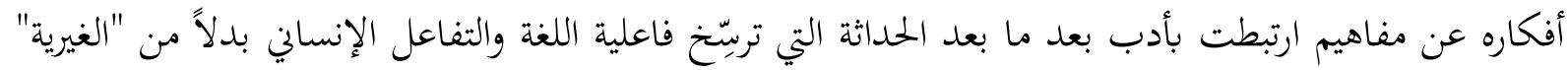

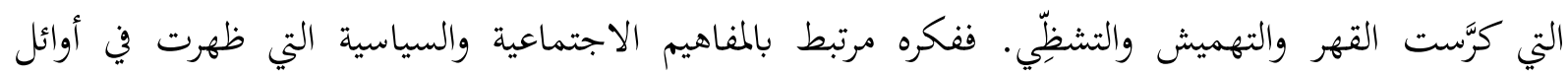

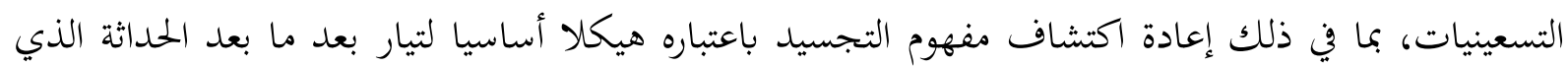

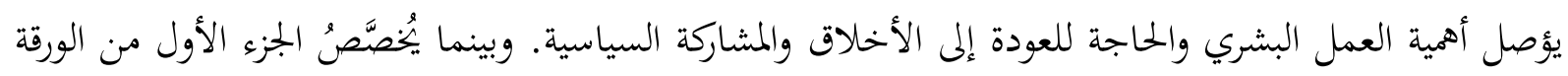

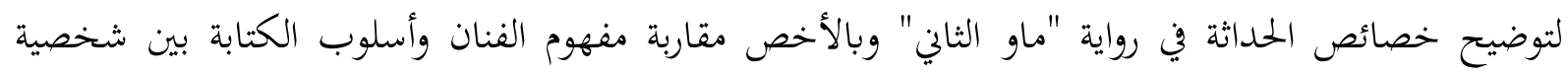
(جراي) والكاتب الحداثي "جيمس جويس" والتي تصور الفنان في رحلة البحث عن الذات والهوية وعلاقة الخيال

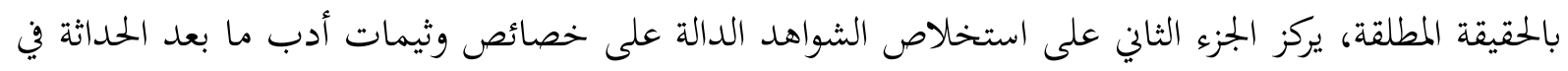

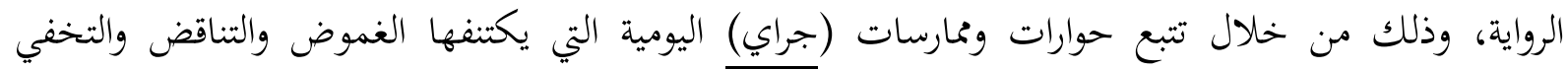

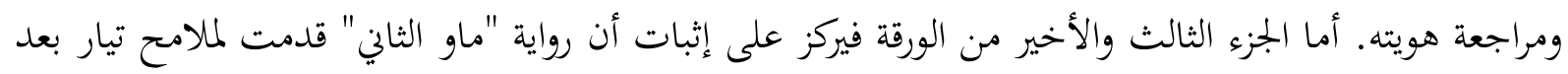

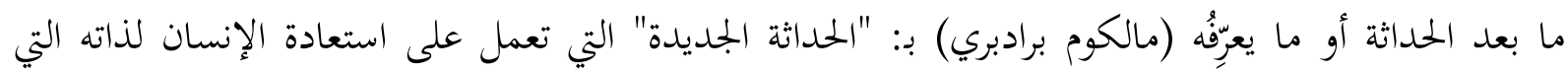

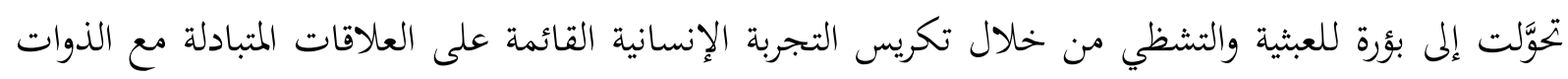

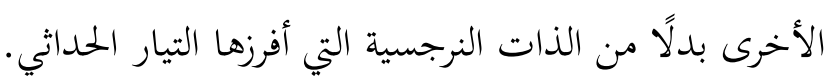

\section{تيار الحداثه: وظيفة الفن الجماليه والبحث عن الذات}

تظهر ملامح أدب الحداثة جلية في عدد من عناصر رواية "ماو الثاني". فالحداثة بمفهومها الشامل ترتبط

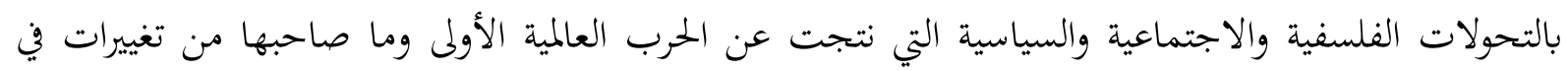

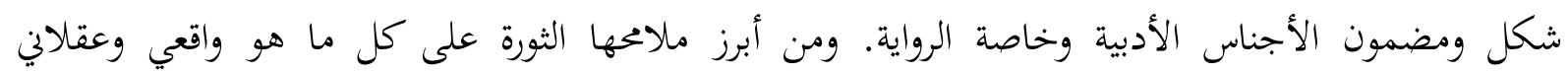

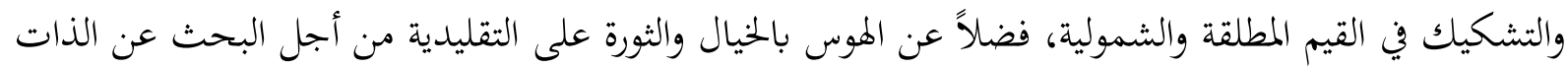

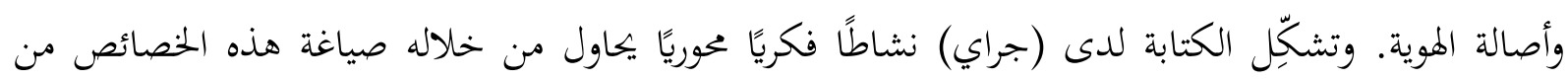

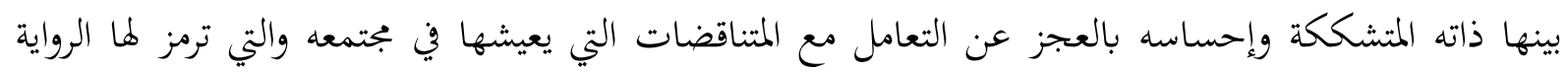


DOI: https://doi.org/10.22452/aldad.vol5no1.2

e-ISSN: 2637-1146

https://ejournal.um.edu.my/index.php/aldaad/index

بعدم قدرته على الانتهاء من كتابة روايته، مما أثََّّ سلبًا على شخصيته وعاداته (ديليلو، ص. r به). وتشكِّل حالة

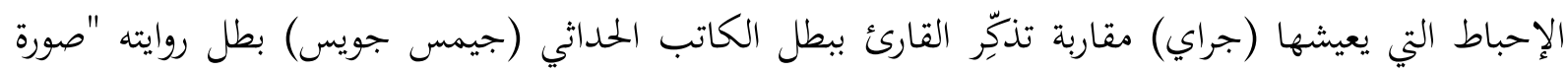

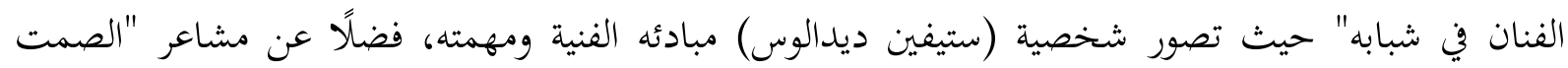

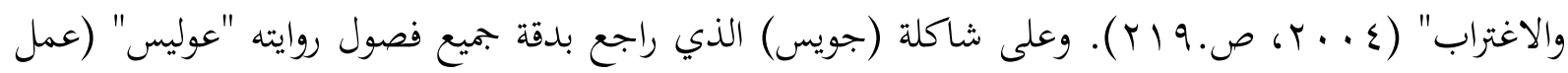

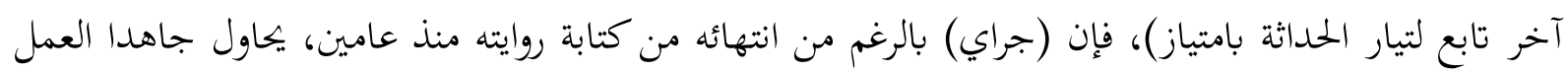

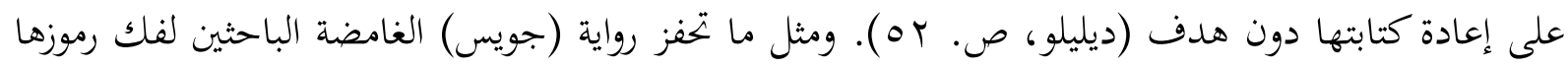

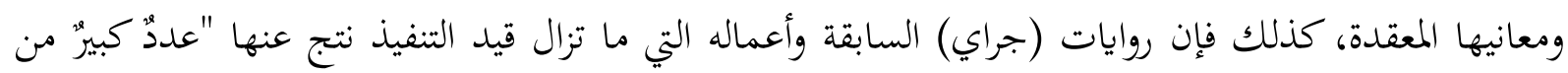

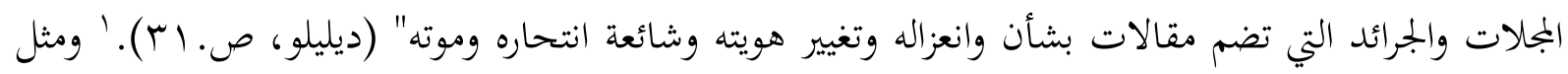

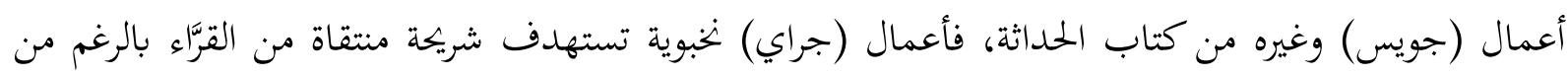

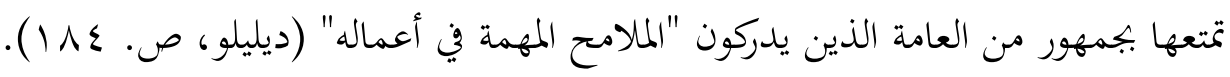

بجانب أوجه الشبه الواضحة بين (جويس) و (جراي)، يؤسس (ديليلو) لتشابه أعمق يتمثل في تأملات

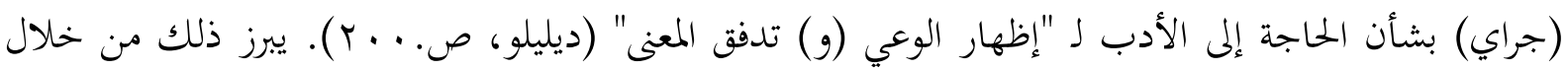

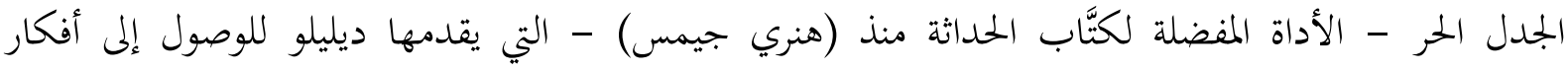

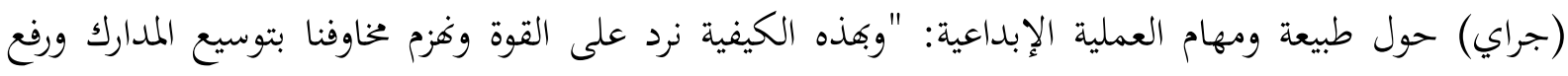

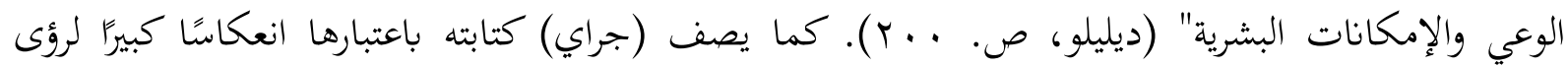

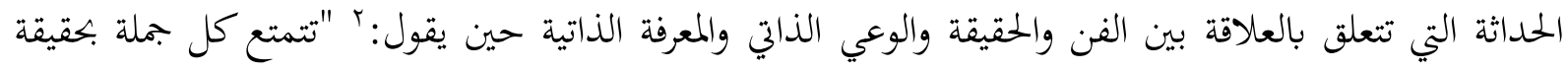

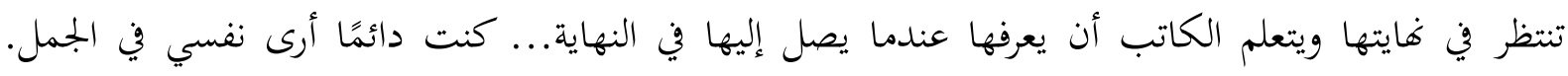

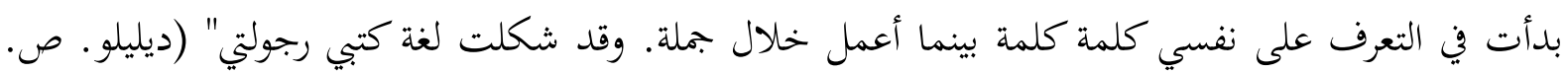

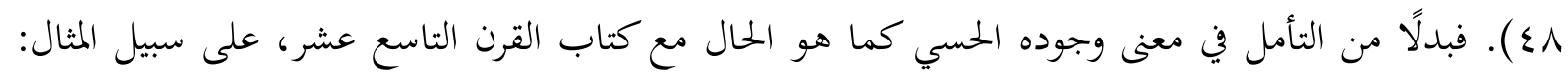

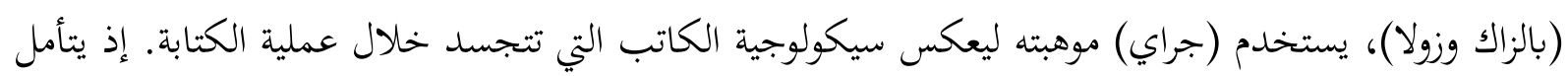

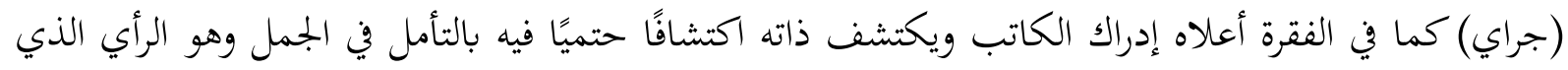

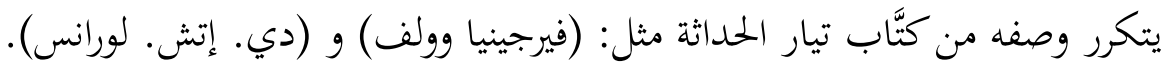

'يربط موران (اماو الثاني) ب 》الانبهار المتناقض بعزلة المؤلف في ثقافة المشاهير الأمريكية) (rV ا)، بما في ذلك (جي.دي. سالينجر)، إلمام رئيسي آخر لأعمال

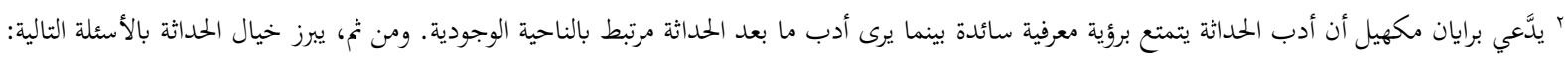

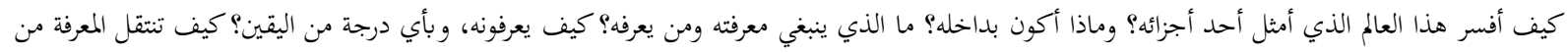

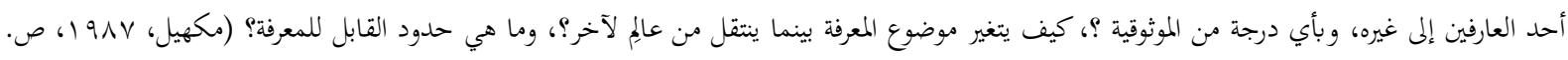


DOI: https://doi.org/10.22452/aldad.vol5no1.2

e-ISSN: 2637-1146

https://ejournal.um.edu.my/index.php/aldaad/index

يجسد (ديليلو) هذه الفكرة من خلال (جين كلاود)، أحد الشخصيات الأخرى في الرواية وهو شاعر

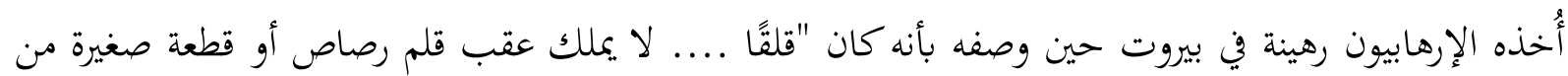

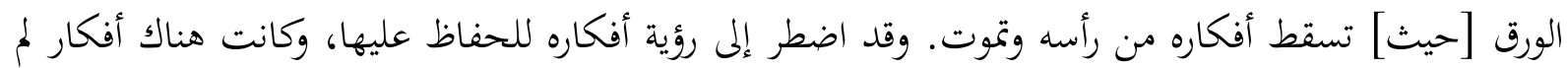

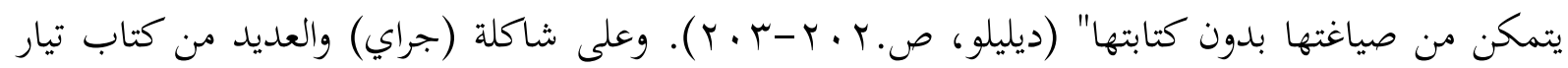

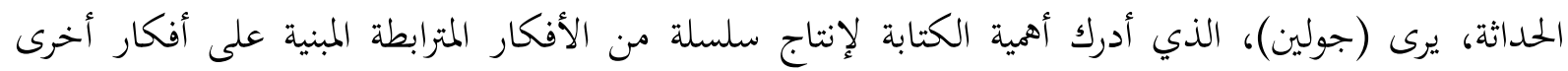

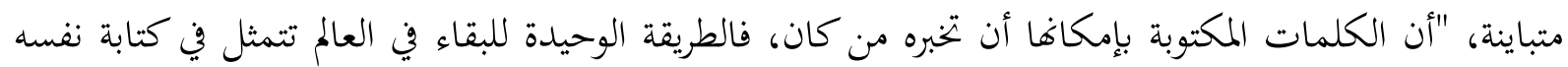

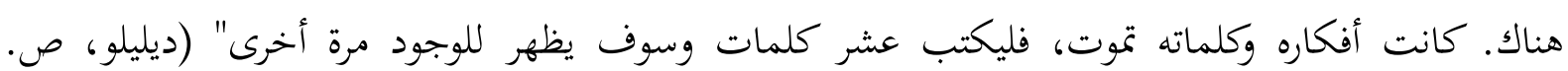

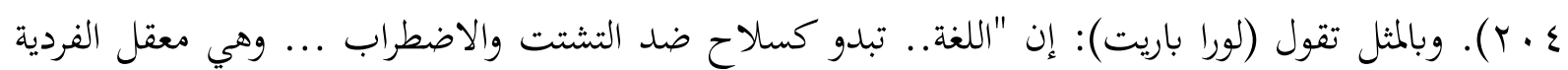

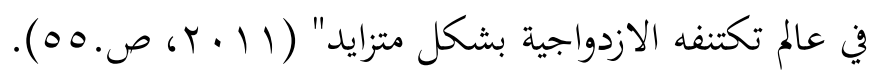

يوضِّح (جراي) لاحقًا أن الكتابة لا تحدف فقط إلى تحسين الوعي الذاتي للشخص وتقوية هويته ولكنها

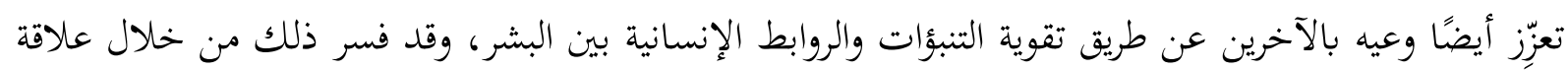

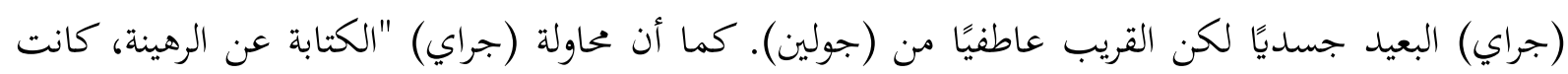

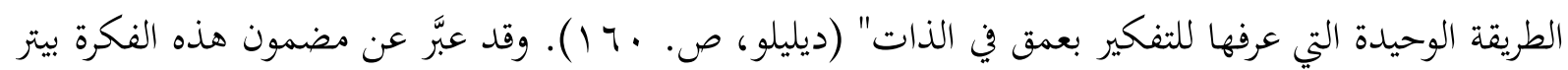

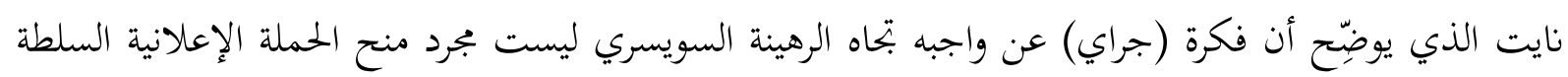

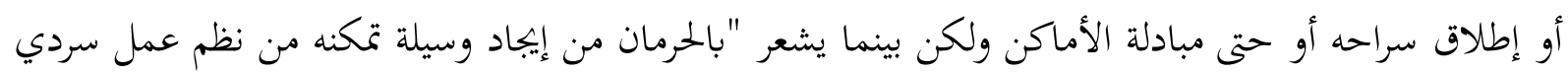

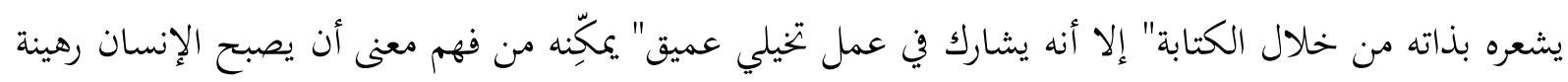

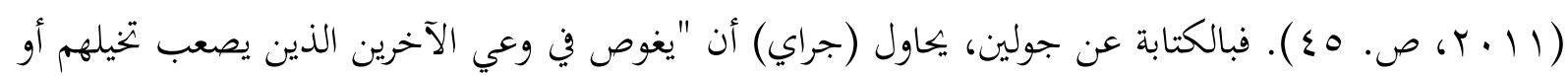

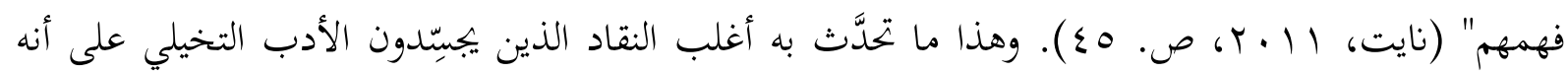

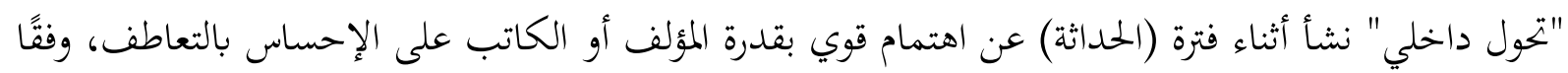

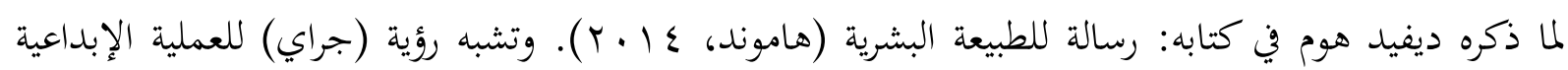

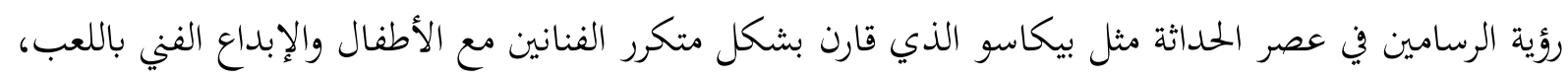

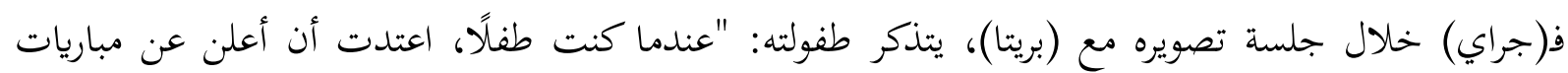

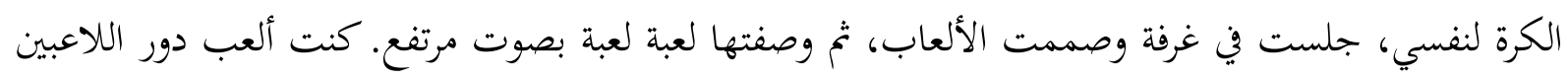

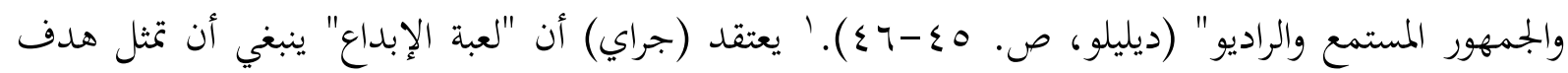

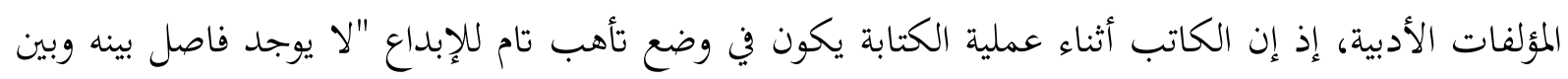


DOI: https://doi.org/10.22452/aldad.vol5no1.2

e-ISSN: 2637-1146

https://ejournal.um.edu.my/index.php/aldaad/index

اللاعبين والغرفة والمجال. كل شيء فريد وشفاف، وتلقائي بشكل كامل. هي لعبة الذات المفقودة بدون شك أو

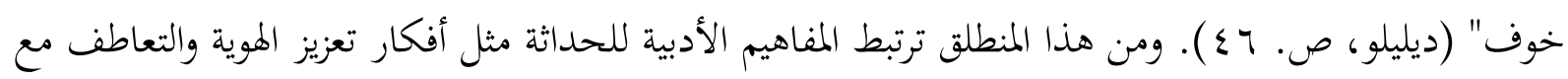
رؤية الحداثة للفن باعتباره عفويًّ وتلقائيًا.'

\section{ما بعد الحمداثة: الهوية الجمعية واللاعقلانية المفرطة}

بالرغم من توفر عناصر الأدب الحداثي المتمثل في شخصية (جراي) في الرواية، إلا أن توجيه الكاتب

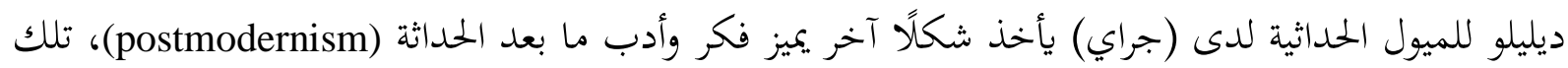

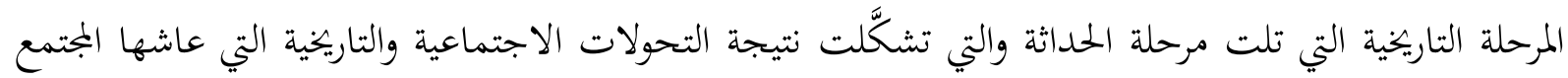
الغربي في خمسينيات القرن الماضي إبان الحرب العالمية الثانية، والتي تميزت بالنزعة الاستهلاكية القائمة على إلغاء وحدة الذات والمركزية لتحل محلها ذات فوضوية، فصامية، ومتشظية تقوض العقل وتعبث بالنظام، وتتبنى

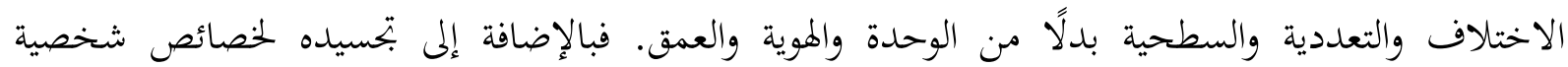

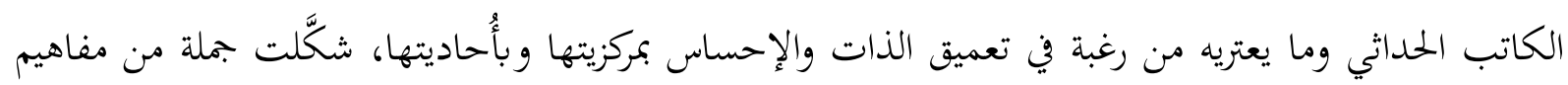

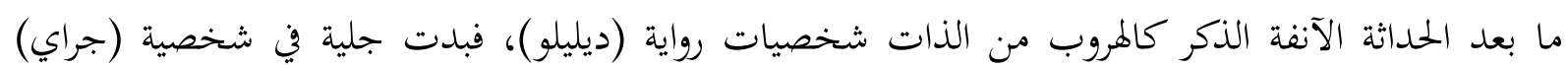

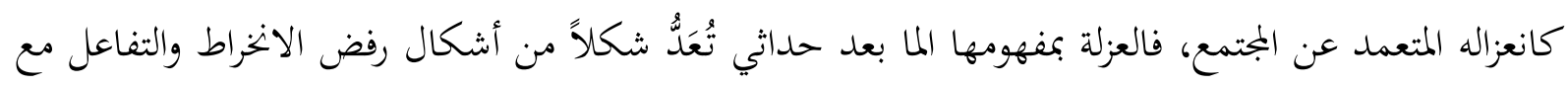

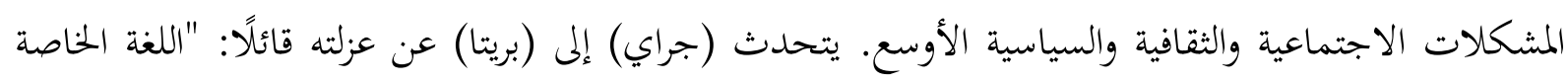

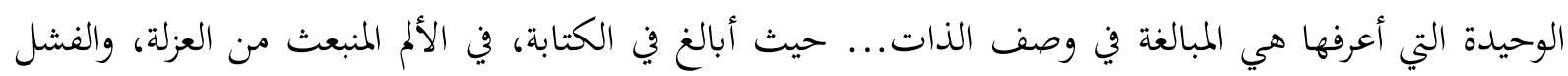

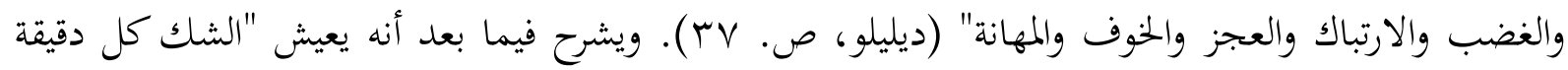

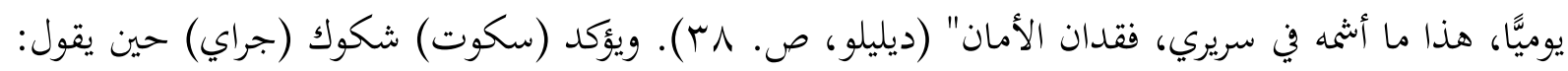

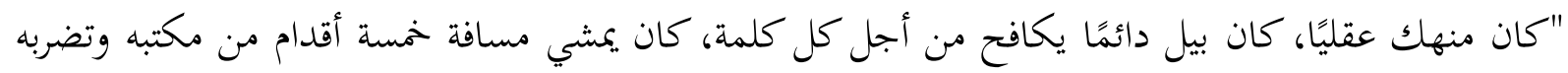

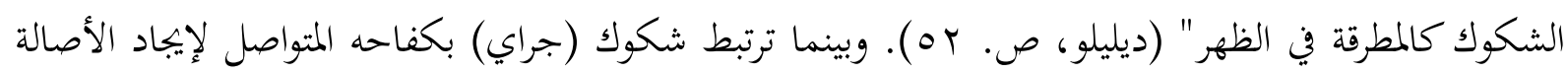

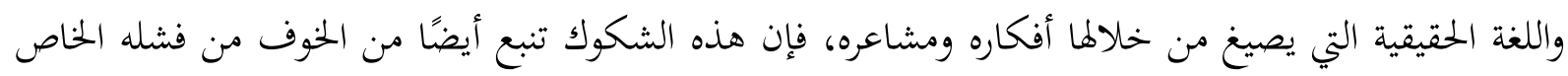

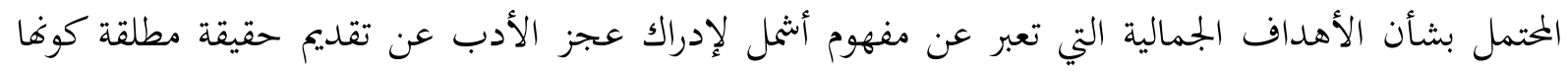

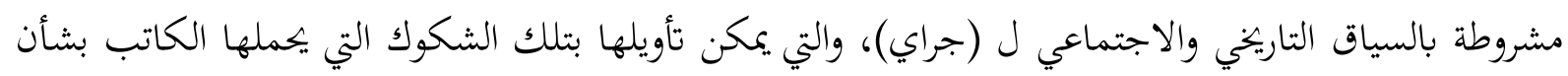

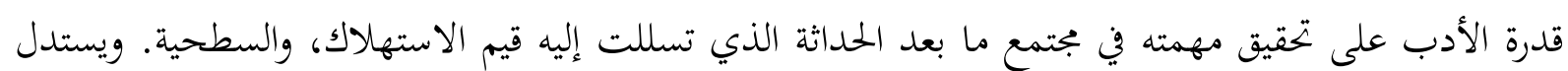

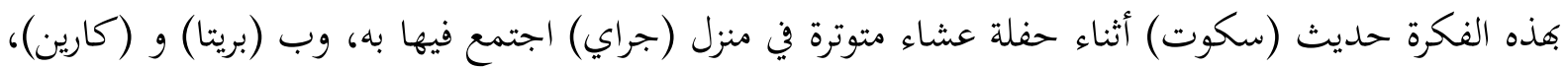
إذ يقول: "اعتادت الرواية على تغذية بحثنا عن معنى ... كانت تمثل السمو الدنيوي العظيم، الحشد اللاتيني للغة منداء 
DOI: https://doi.org/10.22452/aldad.vol5no1.2

e-ISSN: 2637-1146

https://ejournal.um.edu.my/index.php/aldaad/index

والشخصية وأحيانًا الحقيقة الجديدة. ولكن يأسنا أودى بنا إلى شيء أكبر وأكثر ظلامًا. ولذلك نتحول إلى

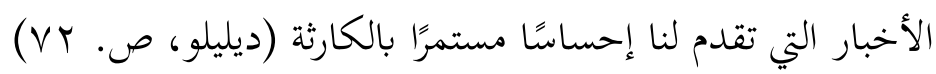

تتجسد سمات ما بعد الحداثة في رواية "ماو الثاني" من خلال تكريس الكاتب لمفهوم الإعلام، بما في

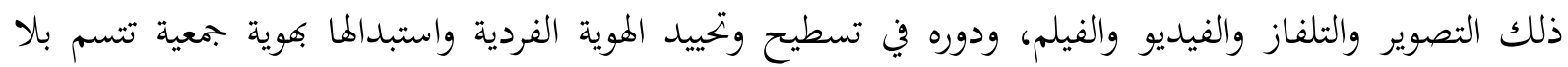

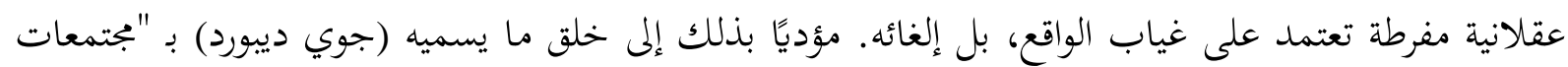

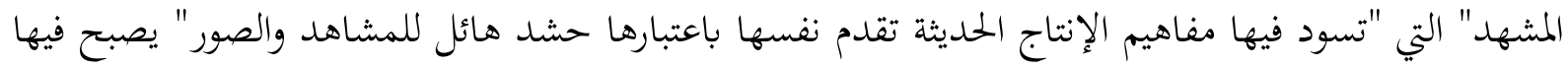

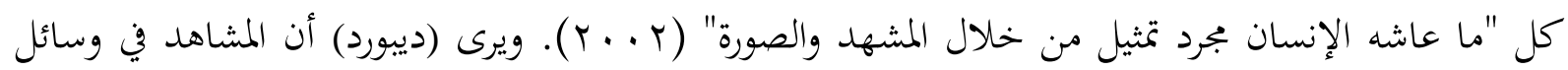

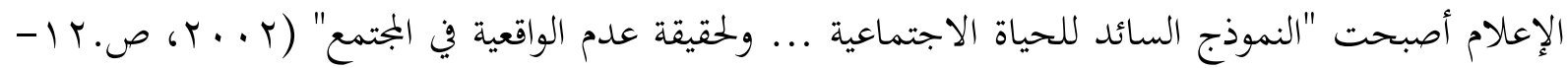

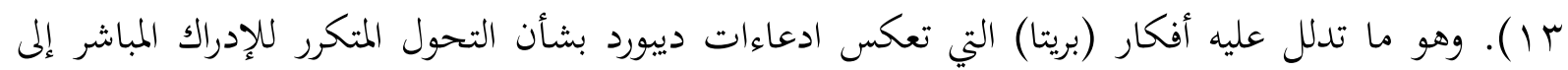

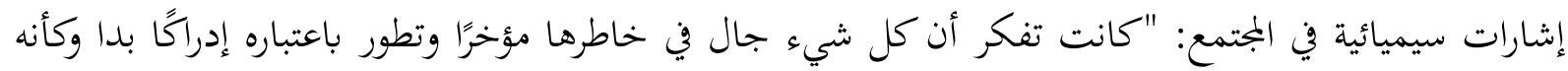

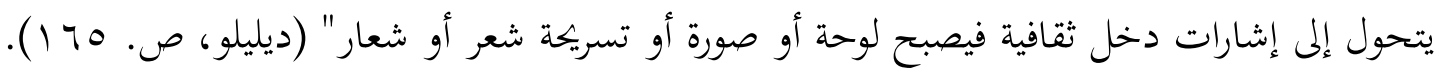

في مقابل ما أفرزته الحداثة من زخم يرتبط بمفهوم الأصالة وصياغة النماذج الثابتة للهوية، فإن التشبع الفان الإعلامي وحالة الفوضى التي أفرزتا ما بعد الحداثة عملت على إذابة الهوية ودججها في تمثيلات لا غهائية (ليوتارد،

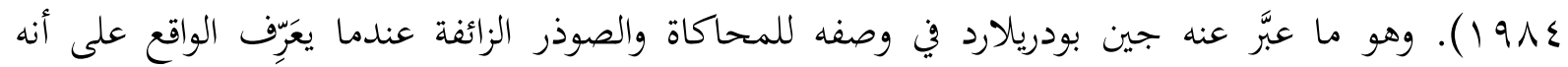

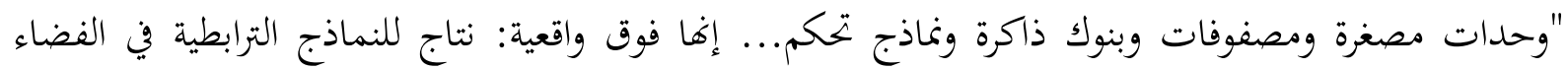

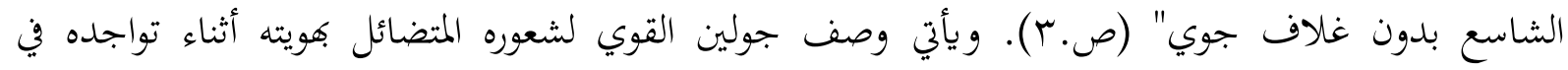

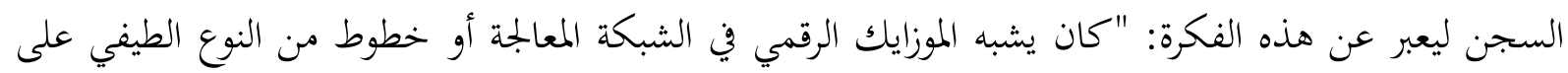

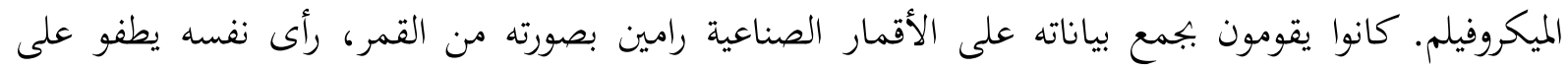

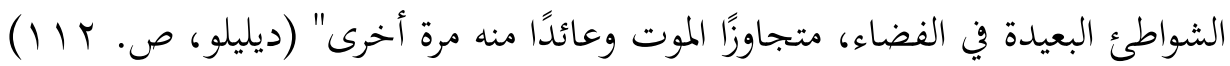

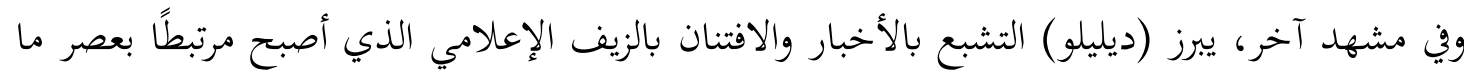

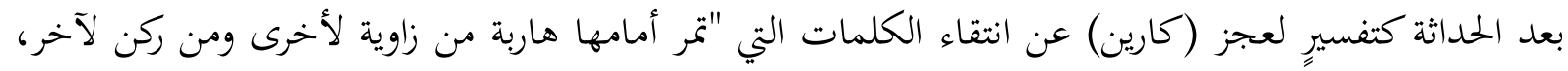

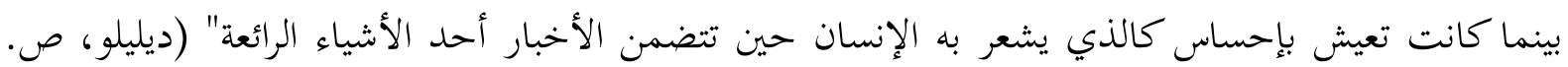
ه1 1). وتعكس هذه الآراء القاتمة بشأن غياب أهمية الأدب في المجتمع المعاصر المتشبع إعلامئًا آراء (ديليلو):

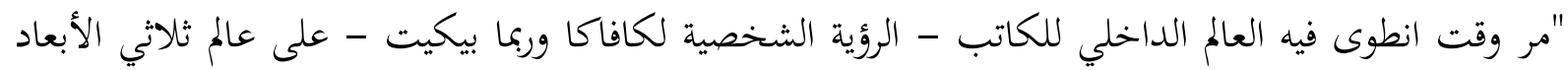

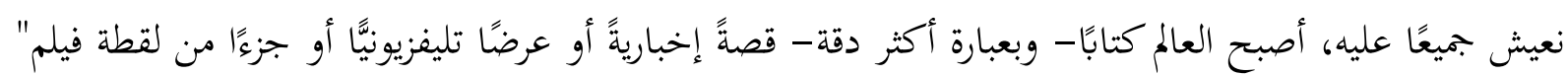

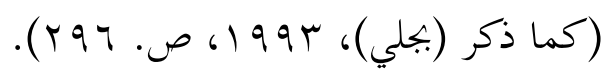


DOI: https://doi.org/10.22452/aldad.vol5no1.2

e-ISSN: 2637-1146

https://ejournal.um.edu.my/index.php/aldaad/index

لا يكتفي (ديليلو) في روايته "ماو الثاني" بتصوير غزو الإعلام لكافة أنماط ومناشط حياة الفرد في عصر

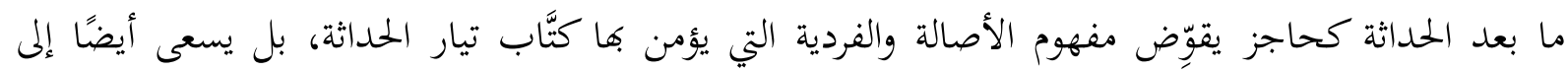

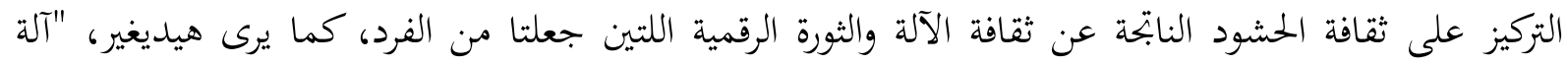

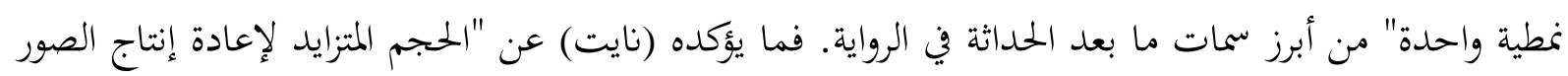

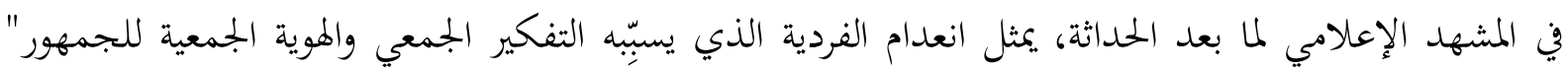

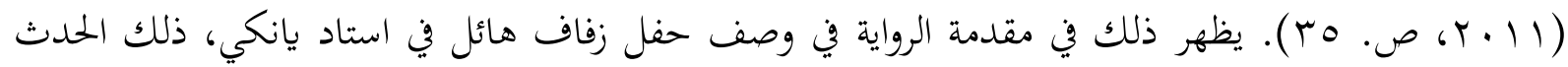

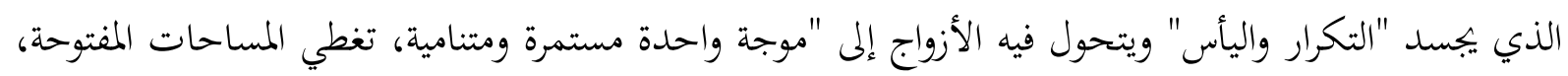

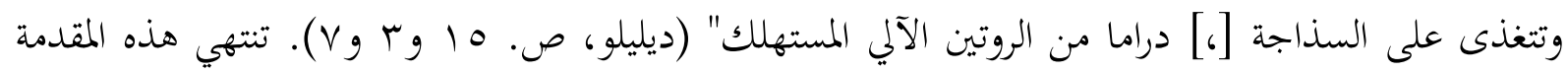

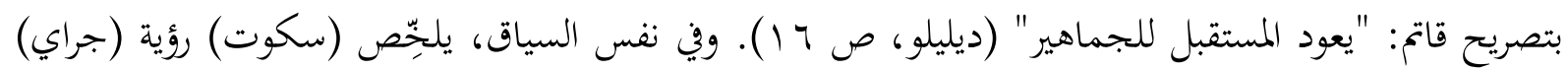

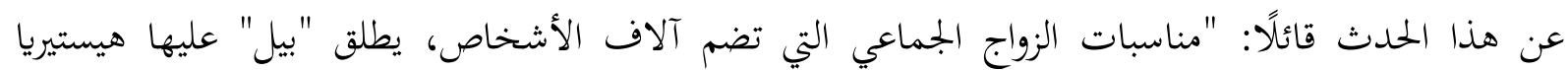

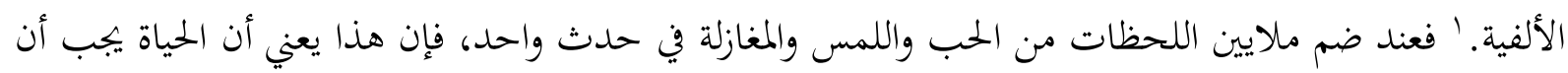

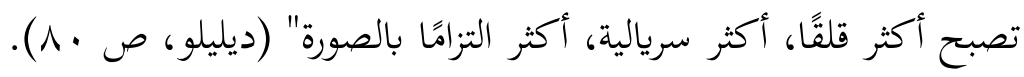

كما يبرز (ديليلو) في الرواية غياب الفردية؟ من خلال وصف (سكوت) مدينة نيويورك وما يكتنف

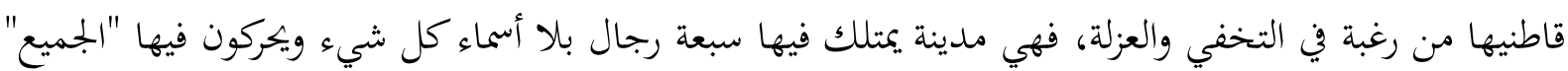

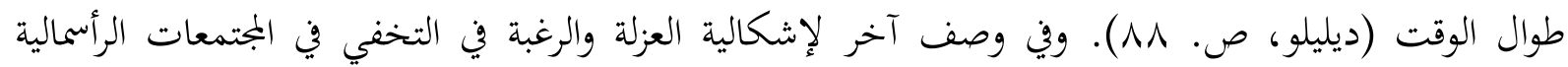

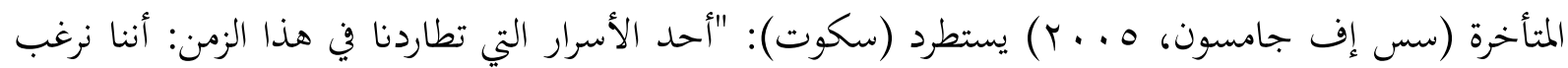

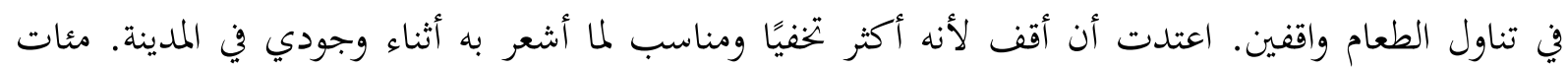
الآلاف من الأشخاص يأكلون وحدهم، يمشون وحدهم، ويتحدثون إلى أنفسهم في الشارع أحاديث عميقة

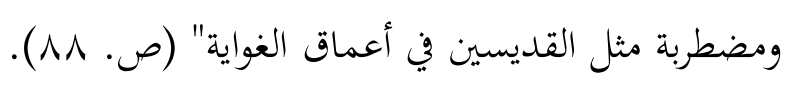

يُبرز التشابه في وصف (سكوت) الصين والولايات المتحدة ملمحًا آخر لمجتمع ما بعد الحداثة: تضاؤل الاختلافات بين الأماكن والثقافات. فالمدن "التي تمثل قمة الرأسمالية الغربية المتقدمة تكنولوجيًا في ما بعد الحداثة التهاثة

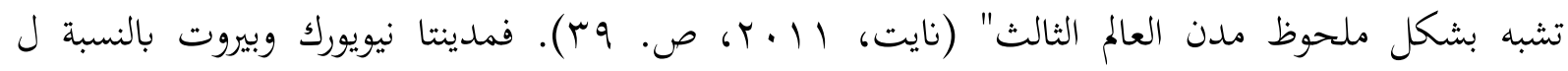

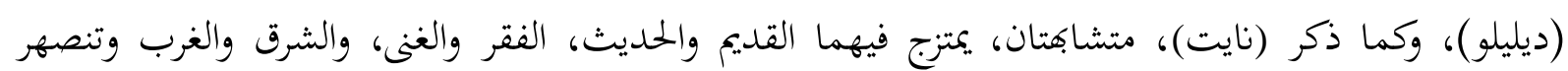

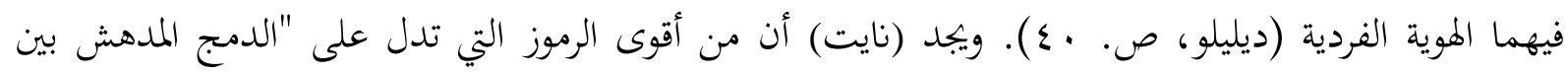


DOI: https://doi.org/10.22452/aldad.vol5no1.2

e-ISSN: 2637-1146

https://ejournal.um.edu.my/index.php/aldaad/index

العالمين الأول والثالث" في رواية (ديليلو) (11 · r، ص. اع) تكمن في لافتات المشروبات الغازية التي تراها (بريتا)

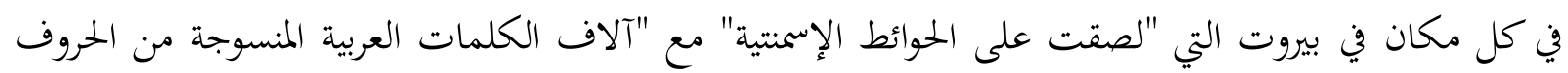

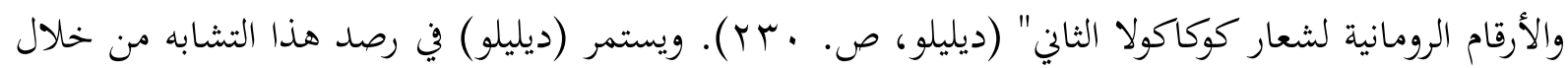

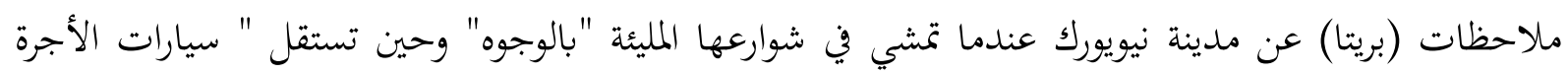

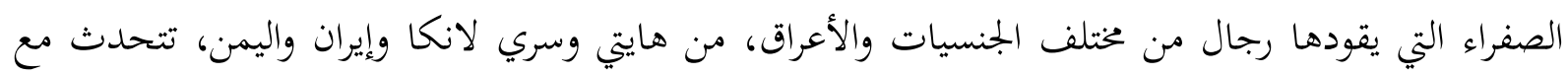
رجل من السيخ وآخر من مصر"، تتقاسم المساحة مع "رجال الأعمال العابرين للطرقات القابعة أسفل الأبراج

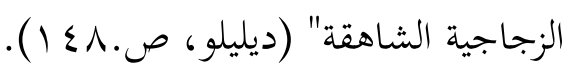

لا تشير هذه المقاربات لمجرد تأثير العولمة في طمس الاختلافات الثقافية فحسب، وفق ما يدِّعي (نايت)،

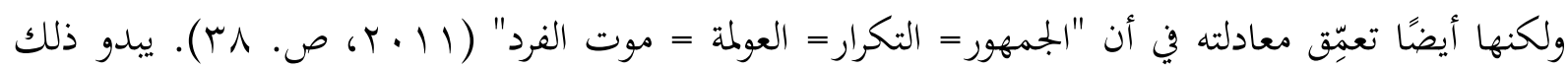

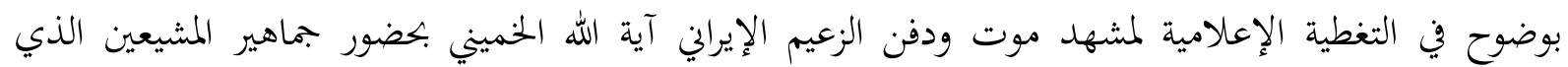

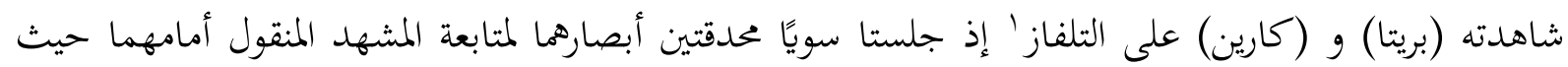

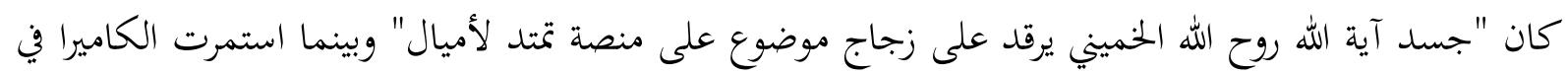

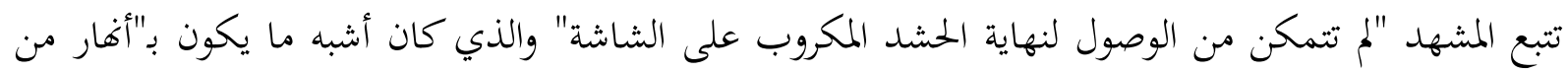

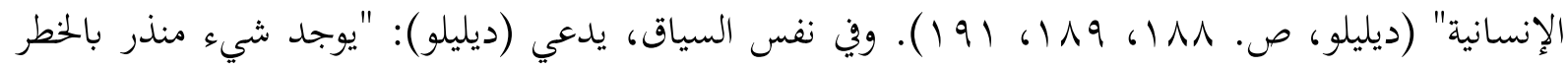

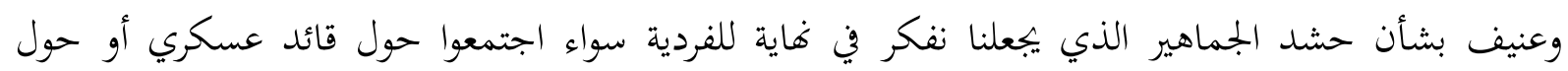

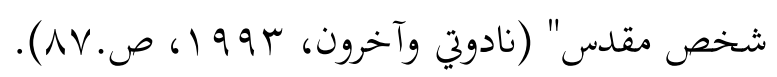

كما يعزز (ديليلو) خصائص ما بعد الحداثة في رواية "ماو الثاني" من خلال منظومة من التقانات

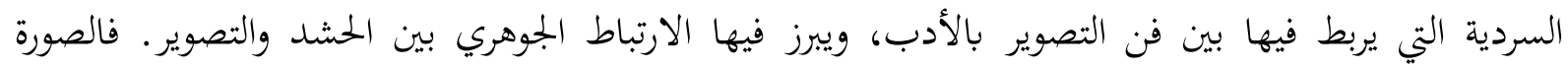

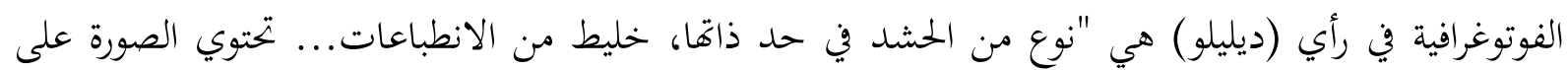

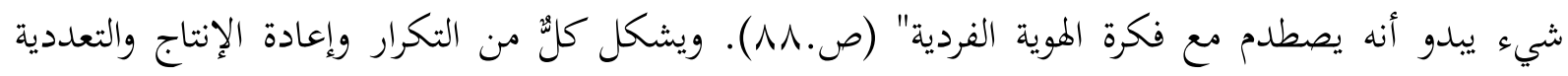

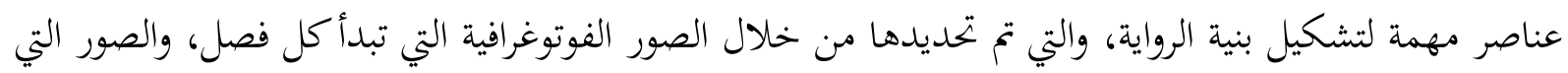

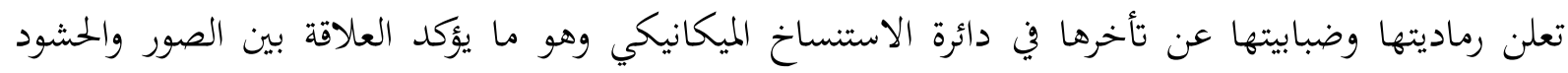

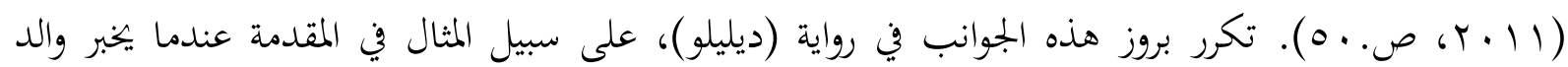

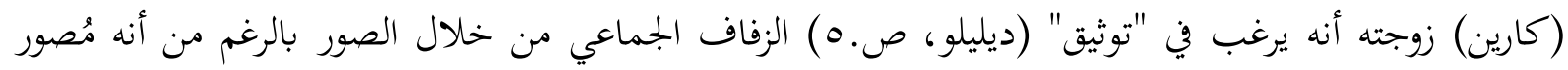

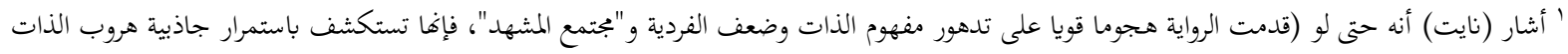

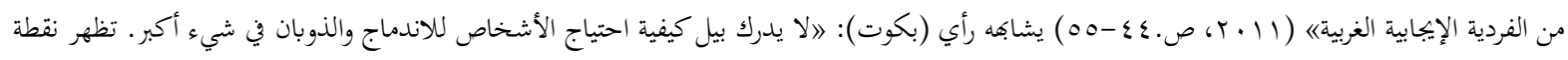

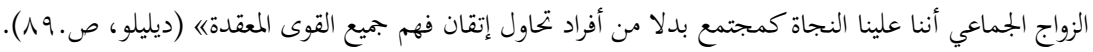


DOI: https://doi.org/10.22452/aldad.vol5no1.2

e-ISSN: 2637-1146

https://ejournal.um.edu.my/index.php/aldaad/index

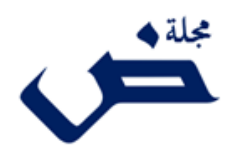

$$
\text { جماعيًا من قبل "آلاف الناس" (ديليلو، ص. • () }
$$

إن محاولة (ديليلو) تكريس العلاقة بين التصوير والحشود من خلال إبراز الهوس بالتوثيق أو استبدال الواقع بالصور، يذكِّر بعبارة (جيمسون) "شهية التصوير" (جيمسون، ه . . ب، ص. 9 9) والتي تعكس في رأيه "علاقة تلصصية مزمنة" بين الأفراد وثقافة ما بعد الحداثة. كما يمكن الاستدلال على هذه الفكرة برأي والتر بنيامين الذي يشجُب الأساليب التي من خلالها يُعاد إنتاج الأعمال الفنية ميكانيكيًا، مثل الصور - كسمة من سمات الرأسمالية - التي فقدت مصداقيتها والتي تتميز بها الأعمال الأدبية في عصر الحداثة (1 (1 ) ). يقول (بنيامين) "أفضل إعادة إنتاج للعمل الفني تفتقر إلى عنصر واحد: حضورها في الوقت والمكان المحددين، ووجودها الفريد في المكان الذي تصادف أن تتواجد فيه" (979 (، ص.3). يثير هذا الأمر توازيًا واضحًا بين غياب الفردية في الحشود والأعمال الفنية المعاد إنتاجها ميكانيكيًا.

ويستخدم (ديليلو) في رواية "ماو الثاني" التناص (Intertextuality) كعنصر أساسي في أدب ما بعد الحداثة. فالتناص كما تعرّفه جوليا كريسيتفا هو تقاطع الخطاب في النص مع نصوص أو خطابات أخرى بصورة ظاهرة أو خفية لتكوين دلالات ومعان أوسع. يبرز ذلك في تقاطع شخصيات الرواية مثل (جراي) و(بيرتا) مع لع شخصية وأعمال آندي وارهول والذي يُبز (ديليلو) من خلاله خصائص أدب ما بعد الحداثة والملتصق بالتعدد والمزج والتنوع وغياب الأحادية والأصالة والتفرد والاستقلالية (هوتشيون، ع . . Y، ص.ع ؟Y) وهو ما عبَّ عنه جيمسون ب "تضاؤل التأثير" والاستهلاكية والتسليع في ثقافة ما بعد الحداثة (جيمسون، م . . ب، ص. • ( ). ويسعى (ديليلو) إلى إيجاد علاقة تناصية مع أعمال أندي وارهول الفنية إلى نقد غير مباشر لأدب ما بعد الحداثة فهو: "لا يفرق بين الأشخاص والأشياء... كصور مارلين مونرو وعلب شوربة كامبل، فهما سلعتين متاحتين

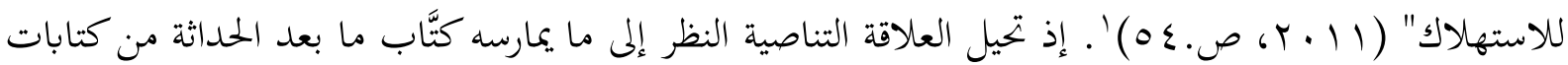
تعتمد على المحاكاة لتولِّد نصوصًا قوامها السطحية والمزج والتشظي. فعقب زيارة معرض وارهول، يقر (سكوت)

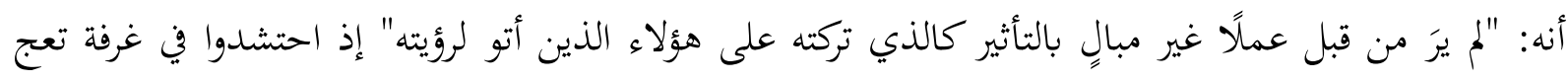
بنسخ مكررة وغير متسقة لصورة الرئيس ماو "ماو الشاشة الحريرية، ماو الخلفية، وماو البوليمر الصناعي" (ديليلو، ص. • - - (Y). وكذلك يتشكل انطباع (بريتا) عند زيارها للمعرض، فهي عندما تقترب من صورة تذكر بعمل وارهول، فإها تفكر في قابلية الفنان للانصهار في بوتقة تمجيد الشخصيات العامة، وفي كيفية دمج الصور" (ديليلو، ص. عـ 1 ). توازي هذه الفكرة ما قاله جيمسون بشأن بورتريه وارهول والذي يؤكد من خلاله أن الأدب

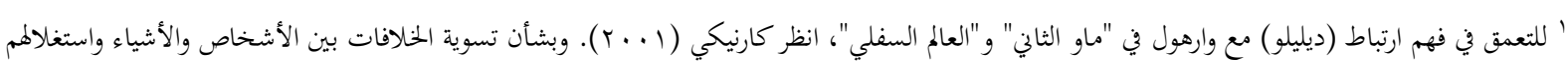

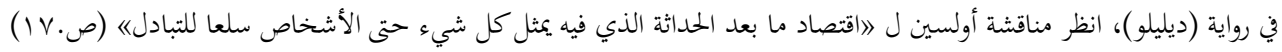


DOI: https://doi.org/10.22452/aldad.vol5no1.2

e-ISSN: 2637-1146

https://ejournal.um.edu.my/index.php/aldaad/index

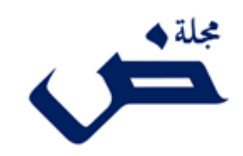

كالتصوير في كونه سلعة. وهو ما "يبدو جليًا في صور مارلين مونرو.

يجسد مفهوم (بريتا) للتصوير نفس مفهوم الكاتب (ديليلو) عن أدب ما بعد الحداثة فهي ترفض الزيف المتولد من التصوير. فبعد عملها في مجال التصوير لسنوات تجد أن " كل ما التقطته من صور بكافة أشكالها ومهما كان مدى الرعب والواقع والتعاسة والأجساد المتعفنة والوجوه الدامية، كل الصور في النهاية جميلة للغاية"

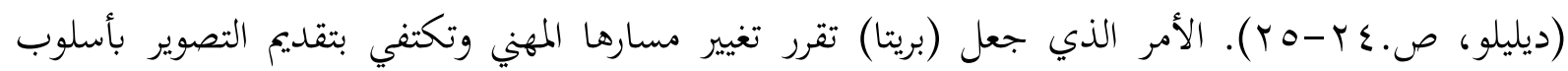
علمي ك"نوع من الإحصاء" الصور التي تلتقطها "لكل [كاتب] تستطيع أن تصل إليه بينما تقلل "الأسلوب والنمط الشخصي إلى الدرجة الممكنة" لخلق "صيغة للمعرفة والذاكرة يمكن حفظها في مكان يصل إليه الجميع. فوجه الكاتب هو المدخل أو المفتاح لإزالة الغموض الداخلي للكاتب" حتى وإن لم يكن عمل الكاتب معروفًا.

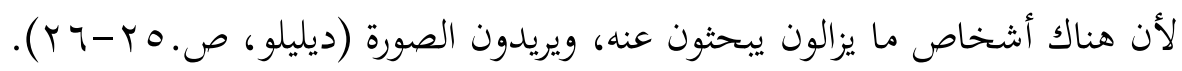

\section{بعد ما بعد الحماثة وتعزيز التجربة الإنسانية}

بحلول التسعينات من القرن الماضي، نشأت تطورات في فلسفة العقل والعلوم الإدراكية والتوجهات الأدبية كرد فعل على الرفض المتزايد لقيم ما بعد الحداثة: كالتشكيك والتشظي والتعددية، إذ بدأ العديد من الكتاب مثل دايفيد فوستير واليس، وجوناثان فرانزن، وجوناثان سافران بتبني قيم ومفاهيم جمالية وأخلاقية تدعو إلى التعامل مع الواقع خارج حدود النص وإلى التفاعل والتواصل مع العالم من حولم. بيد أنه لا توجد أطر تنظيرية واضحة لهذا التيار بعد، إلا إن هؤلاء الكتّاب وغيرهم قاموا بتعريف أهم هذه القيم التي من بينها: بتحاوز مفهوم موت الإنسان، إحياء مفهوم الذات، وتعزيز التجربة الإنسانية والتفاعل مع العالم الخارجي. كما تبنَّى هؤلاء الكتاب الاهتمام بالعلاقات الأسرية والصراعات الثقافية والتركيز على قضايا الهوية والأصالة والواقعية وتمثيلاتما. (يوسف، V V • †). علاوة على ذلك، فإن تيار بعد ما بعد الحداثة يتّبع الأسلوب السردي الواقعي لتقديم منظور واسع للواقع السياسي والاجتماعي والثقافي للعصر من أجل سد الفجوة بين النص والواقع.

فعلى النقيض من كتاب ما بعد الحداثة، لا يؤمن كتَّاب بعد ما بعد الحلداثة باغيار كل ما هو ذا قيمة بما في ذلك البشر وإنسانيتهم. فهم يؤمنون بالضرورة الملحة للاستجابة للسياقات التاريخية والاجتماعية والثقافية للعصر وإلى بحارب الناس الحقيقية. وهو ما يهاجج به إدوارد سلينجرلاند حين يؤكد على ضرورة تأسيس "نموذج خاص من البشر القادرين على استخدام اللغة مكونًا ثقافيًا جوهريًا يرتبط بفكرة أن خبرة الإنسان عن العالم لا لإن تتكون من اللغة فقط" (N . . r، ص. V^) وأن الوصول لإدراك مباشر للحقيقة يتطلب التفاعل مع واقع الأشياء 
DOI: https://doi.org/10.22452/aldad.vol5no1.2

e-ISSN: 2637-1146

https://ejournal.um.edu.my/index.php/aldaad/index

التي لا تكون ذات معنى حقيقي إلا من خلال الشبكات السيميائية اللغوية أو البصرية والتي يستطيع من خلالها

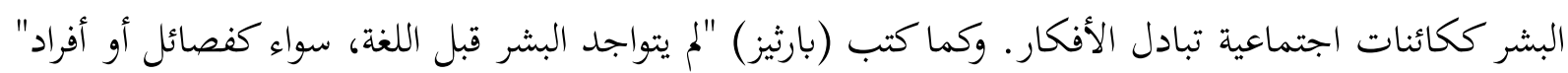

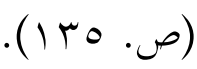

تبرز مفاهيم تيار بعد ما بعد الحداثة في رواية "ماو الثاني" من خلال (جراي) الذي تنشأ بينه وبين بيرتا

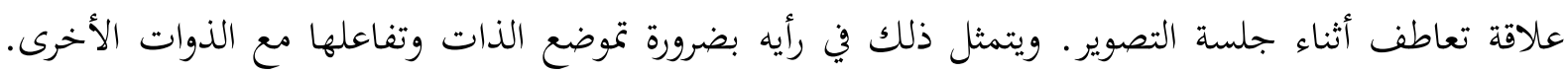

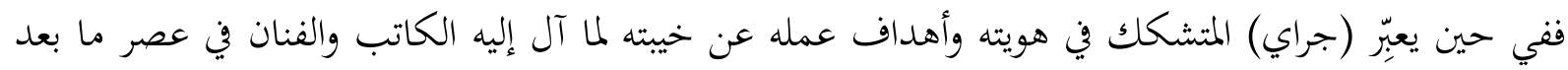

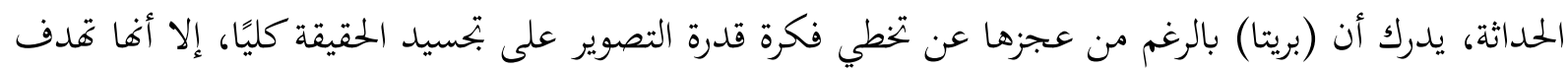

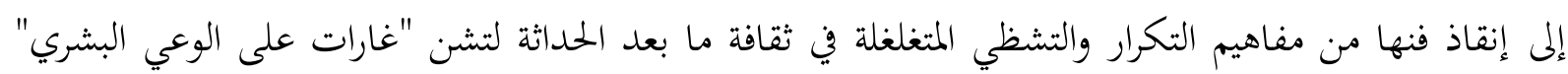

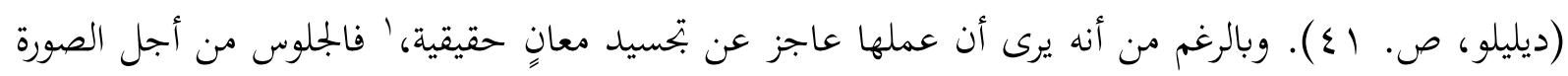

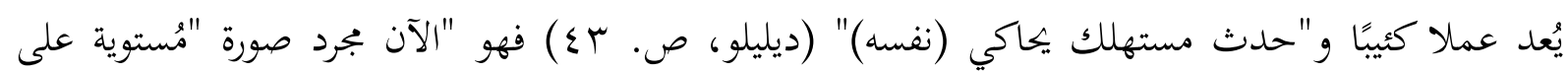

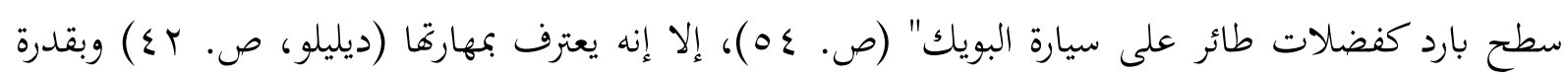

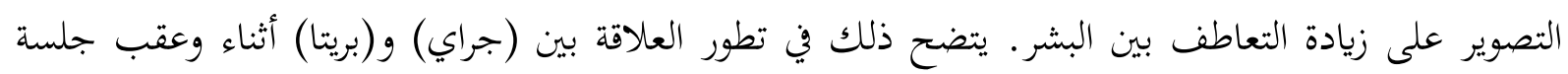

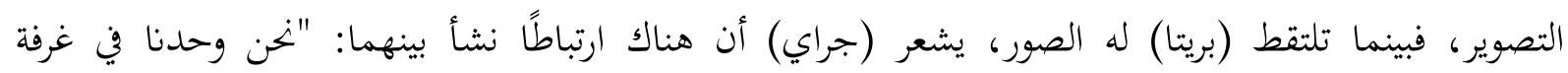

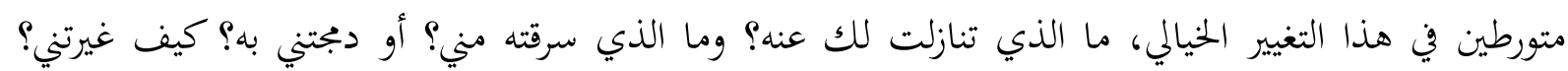

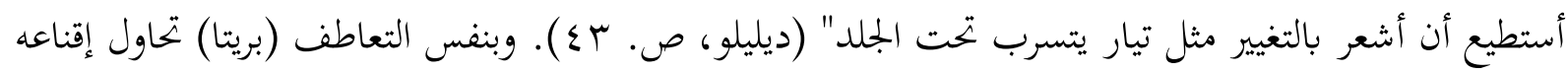

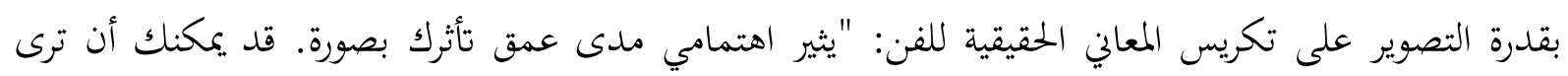

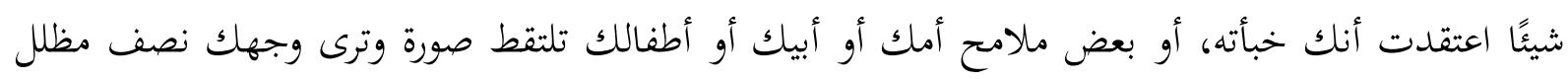

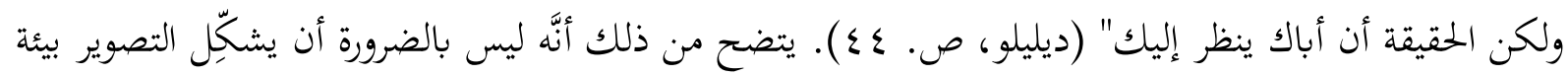

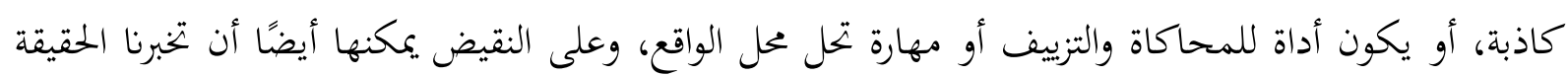
بشأن المصور والنموذج والعالم.

وتبرز رواية ديليلو بقوة الأهمية الجوهرية للجسد في التجربة الإنسانية بما يتماشى مع تيار بعد ما بعد

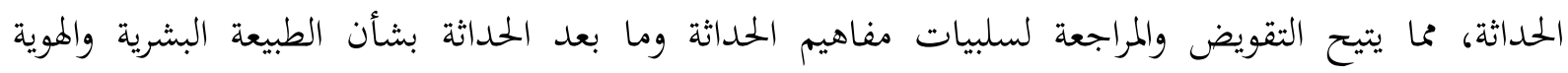
والإبداع. ويتضح ذلك في تأمل (جراي) لجسده: "إذا كتب شخص ما سيرته الذاتية الحقيقية، فسوف تمثل الآمه

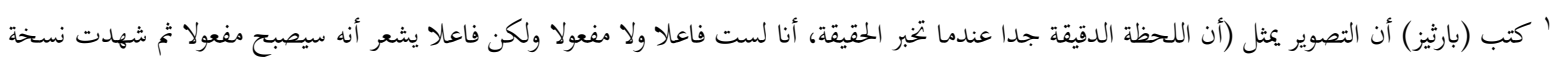

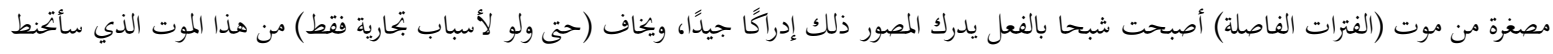

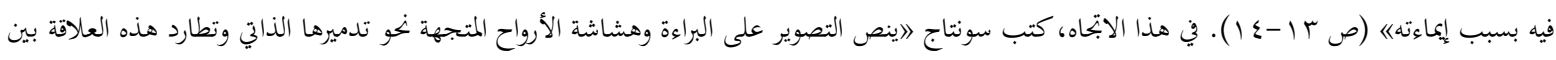

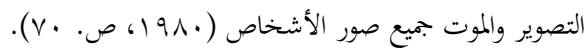


DOI: https://doi.org/10.22452/aldad.vol5no1.2 e-ISSN: 2637-1146 https://ejournal.um.edu.my/index.php/aldaad/index

النابتحة عن الغازات في معدته وضربات قلبه، وأسنانه المطحونة، والتهجيات المشوشة والأنفاس المخنوقة" جزءًا كبيرًا

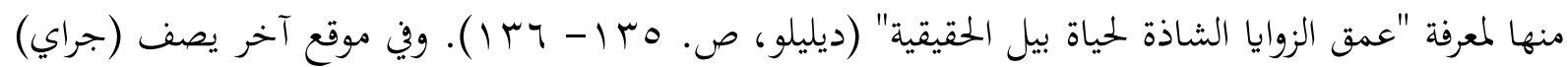

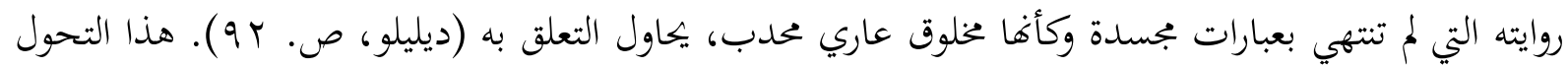

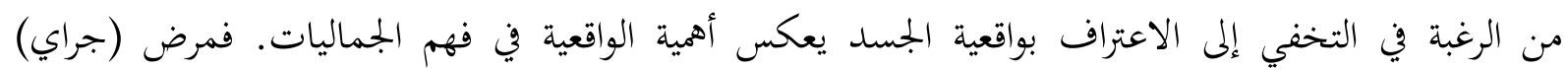

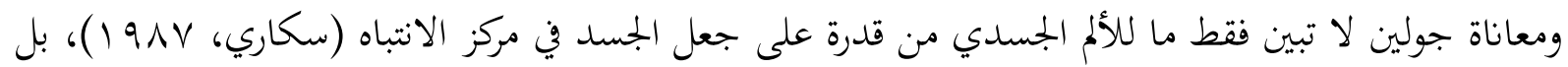

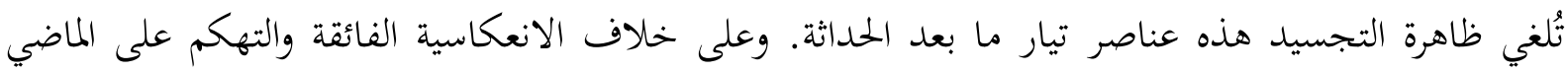

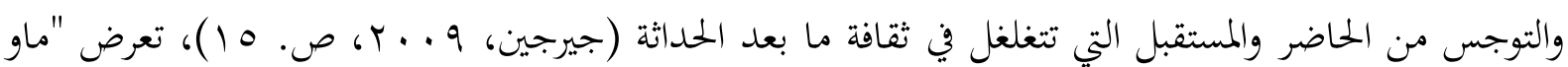

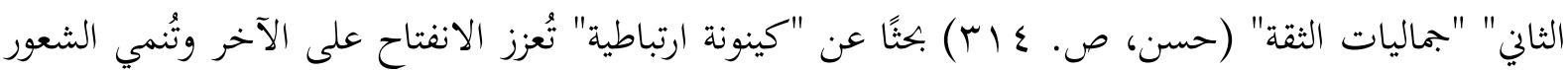
بالمسؤولية والمشاركة الاجتماعية والأخلاقية والسياسية.

من هنا يتضح أن حقيقة المؤلف وبتحاربه كما يرى كُتَّاب تيار بعد ما بعد الحداثة لا تكمن في نماذج

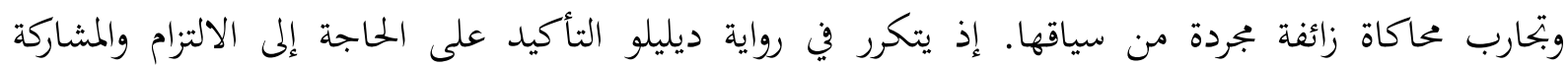

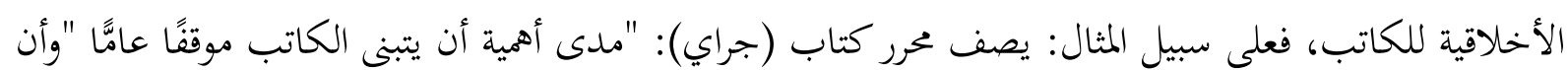

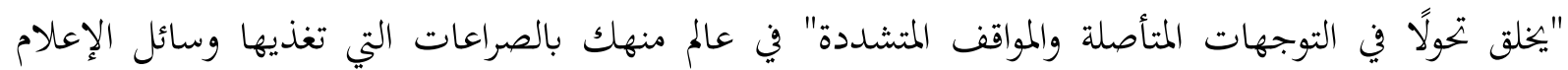

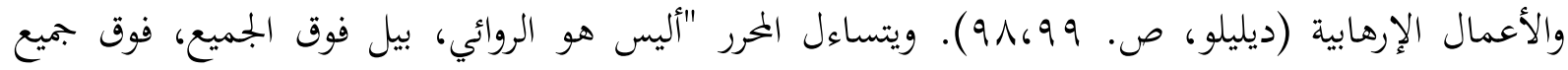

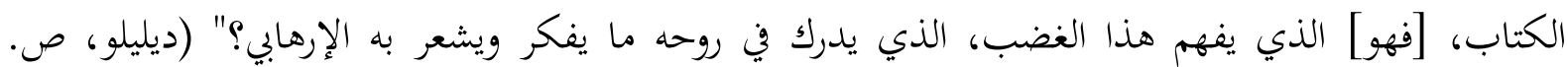

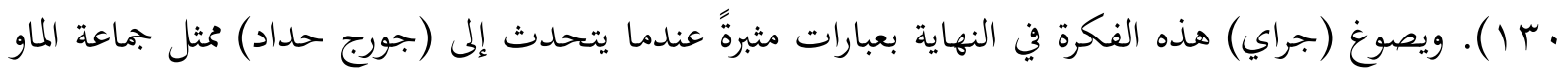

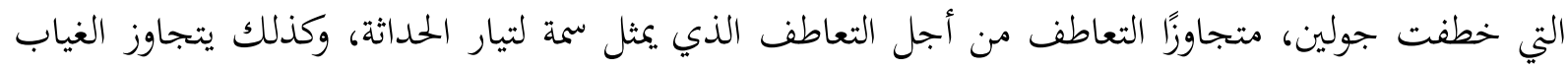

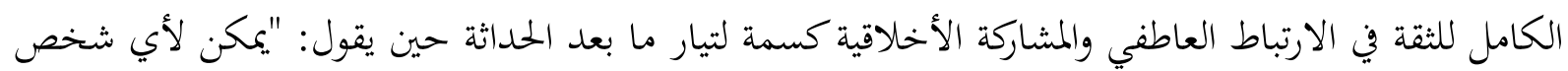

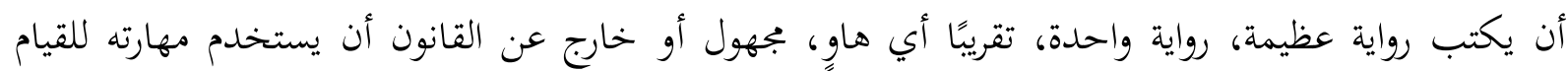

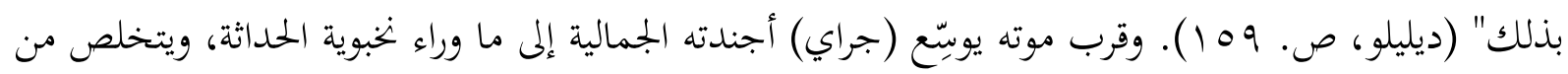

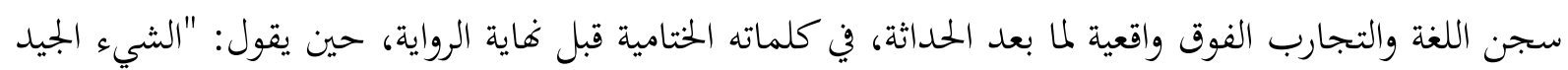

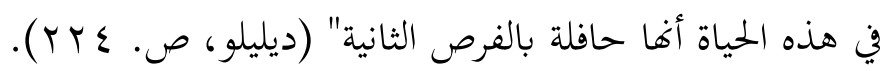

الخاتمة

تظهر هذه الدراسة كيف تمثل رواية "ماو الثاني" بطل الرواية (بيل جراي) باعتباره نموذجًا لجماليات الفترات الثلاث: الحداثة، وما بعد الحداثة، وبعد ما بعد الحداثة. فبينما تظهر الرواية في رسم شخصية بطل الرواية (بيل

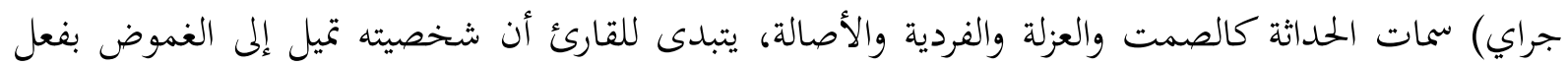




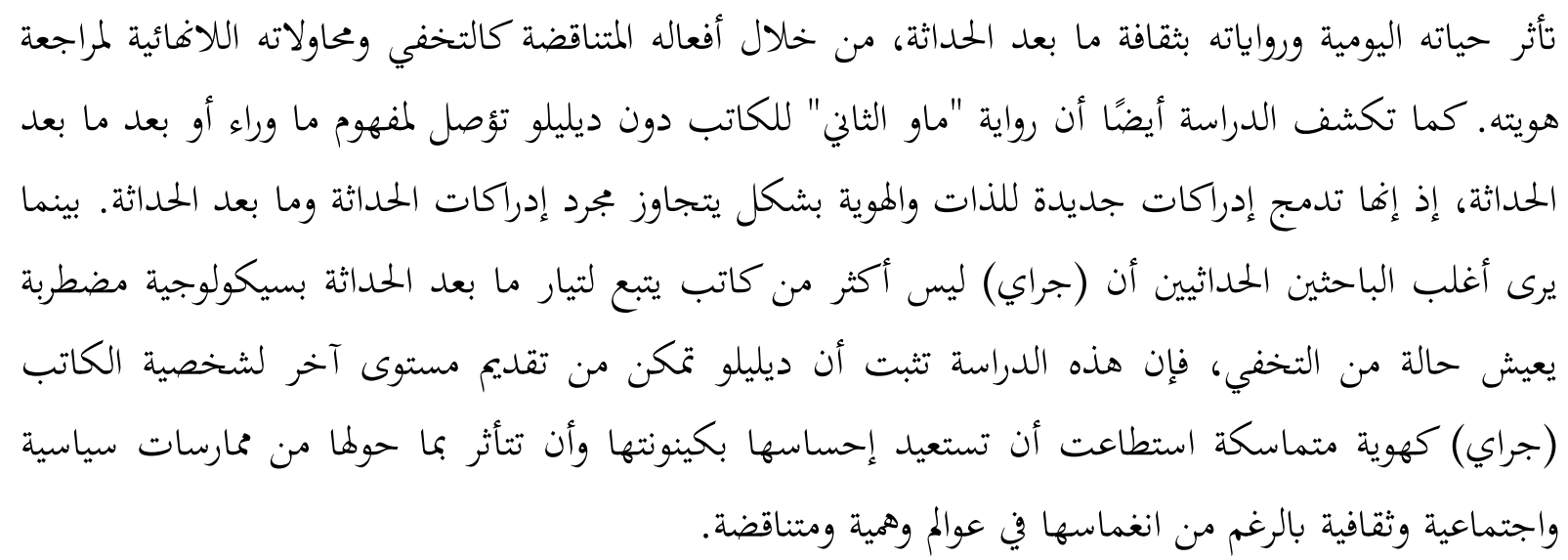

\section{References}

Baker, P. (1994). The terrorist as interpreter: Mao II in postmodern context. Postmodern Culture, 4(2), 34. doi:10.1353/pmc.1994.0002.

Barrett, L. (2011). Mao II and mixed media. In S. Olster (Ed.) Don DeLillo: Mao II, underworld, falling man (pp. 49-68). Continuum.

Barthes, R. (1972). To write: An intransitive verb? In R. Macksey and E. Donato (Eds.) The structuralist controversy: The languages of criticism and the sciences of man (pp. 134144). Johns' Hopkins university press.

Barthes, R. (1977). The Death of the Author. Image-music-text (S. Heath, Trans.). (pp. 142148). Fontana.

Barthes, R. (1982). Camera lucida: Reflections on photography. New York: Hill and Wang.

Begley, A. (1993). The art of fiction CXXXV: Interview with Don DeLillo. The Paris

Review, 128, 274-306. https://www.theparisreview.org/interviews/1887/the-art-offiction-no-135-don-delillo.

Benjamin, W. (1969) . The work of art in the age of mechanical reproduction. In H. Arendt (Ed.) Illuminations (pp. 1-26). New York: Schocken Books.

Bradburry, M. (1995). What was post-modernism: The arts in and after the cold war. International Affairs, 71(4), 763-774. http://doi.org/10.2307/2625097

Canetti, E. (1984). Crowds and power. Farrar. New York: Straus and Giroux.

Debord, G. (2002). The society of the spectacle. Detroit: Black \& Red.

DeLillo, D. (1991). Mao II. New York: Picador.

Gergen, K.J. (2009). Relational being: Beyond self and community. Oxford: Oxford university press.

Green, J. F. (1995). Last days: Millennial hysteria in Don DeLillo's Mao II. In The Endings of epochs. English Association. (pp. 129-148). New York: D. S. Brewer.

Hammond, M.M. (2014). Empathy and the psychology of literary modernism. Edinburgh: Edinburgh university press.

Hardack, R. (2004). Two's a crowd: Mao II, Coke II, and the politics of terrorism in Don DeLillo. Studies in the Novel, 36(3), 374-392. https://www.jstor.org/stable/20831902.

Harvey, D. (1991). The condition of postmodernity: An enquiry into the origins of cultural change. Oxford: Wiley-Blackwell.

Hassan, I. (1961). Radical innocence: Studies in the contemporary American novel. Princeton: Princeton university press. 
Hassan, I. (2003). Beyond postmodernism: Towards an aesthetics of trust. In K. Stierstorfer (Ed.), Beyond postmodernism: Reassessments in literature, theory, and culture. (pp. 199-212). Berlin: De Gruyter.

Hutcheon, L. (2004). A poetics of postmodernism: History, theory, fiction. Routledge.

Jameson, F. (2005). Postmodernism, or, the cultural logic of late capitalism. Durham: Duke university press.

Joyce, J. (2004). A portrait of the artist as a young man and Dubliners. Barnes \& Noble.

Karnicky, J. (2001). Wallpaper Mao: Don DeLillo, Andy Warhol, and seriality. Critique: Studies in Contemporary Fiction 42(4), 339-356. doi:10.1080/00111610109601149.

Knight, P. (2011). Mao II and the New World Order. In S. Olster (Ed.) Don DeLillo: Mao II, Underworld, falling man (pp. 34-48). London-New York: Continuum.

Lyotard, J.F. (1984). The postmodern condition: A report on knowledge. (G. Bennington and B. Massumi, Trans). Minneapolis: Manchester university press. (Original work published 1979).

McHale, B. (1987). Postmodernist fiction. New York: Methuen, Inc.

Moran, J. (2000). Don DeLillo and the myth of the author-recluse. Journal of American Studies, (34(1), 137-152. doi: https://www.jstor.org/stable/27556769.

Nadotti, M., et al. (1993). An interview with Don DeLillo. Salmagundi, (100), 86-97. https://www.jstor.org/stable/40548688.

Scarry, E. (1987). The body in pain: The making and unmaking of the world. Oxford: Oxford university press.

Slingerland, E. (2008). What science offers the humanities: Integrating body and culture. Cambridge: Cambridge university press.

Yousef, T. (2017). Modernism, post-modernism, and metamodernism: A critique. International Journal of Language and Literature, 5 (1), 33-43. http://doi.org/ 10.15640/ijll. v5n1a5. 